\title{
Systematic and Comprehensive Literature Review of Publications on Direct Cerebral Oxygenation Monitoring
}

\author{
Erhard W. Lang ${ }^{*}, 1$ and Matthias Jaeger ${ }^{2}$ \\ ${ }^{I}$ Neurosurgery Associates, Red-Cross Hospital, Kassel, Germany \\ ${ }^{2}$ Department of Neurosurgery, University of New South Wales and University of Western Sydney, Liverpool Hospital, \\ Sydney, Australia
}

\begin{abstract}
This review has been compiled to assess publications related to the clinical application of direct cerebral tissue oxygenation (pbtO2) monitoring published in international, peer-reviewed scientific journals, or major meeting reports published as journal supplements. Its goal was to extract relevant, i.e. positive and negative, information on indications, clinical application, safety issues and impact on clinical situations, as well as treatment strategies in neurosurgery, neurosurgical anaesthesiology, neurosurgical intensive care, neurology, and related specialties. For completeness' sake it also presents related basic science research and case reports. This review is an update of its previous edition published elsewhere in 2007. This review reflects publications from 2004 to 2012. Only relevant publications prior to 2004, which explicitly addressed or systematically examined the above issues, are included in this review and are listed in the reference section. Based on 349 citations it is the most comprehensive review available on direct cerebral oxygen monitoring to this date.
\end{abstract}

Keywords: Review, cerebral oxygenation, raumedic, licox, neurotrend, cerebral partial pressure of oxygen, brain tissue oxygenation.

\section{METHODS}

This review is based on a systematic "Medline" literature search using the following search terms: licox, neurotrend, neurovent, raumedic, brain tissue oxygen, brain tissue oxygenation, cerebral oxygenation, cerebral tissue oxygen, cerebral partial pressure of oxygen, btO2, ptiO2, pti $(\mathrm{O}) 2$, ptiO(2), pbrO2, $\mathrm{PBr}(\mathrm{O} 2), \mathrm{P}(\mathrm{bt}) \mathrm{O}(2), \mathrm{P}(\mathrm{br}) \mathrm{O}(2), \mathrm{PbrO}(2)$, $\mathrm{BTpO} 2, \mathrm{tP}(\mathrm{O} 2), \mathrm{PbO} 2, \mathrm{PbtO} 2, \mathrm{Pbto}, \mathrm{PbtO}(2)$.

Only few publications were not retrieved using this technique. They were, however, identified through personal communication with scientists in the field, meeting proceedings and reviewer assignments. This strategy provided sufficient certainty that relevant papers have not been missed. Unpublished meeting abstracts and published conference proceedings were excluded for this review expect for few which provided comparative studies between different probes. To address relevant matters, related to specific pbtO2 issues, selected non-peer reviewed papers published in supplements were also used only when no other peer-reviewed information was available.

\section{RESULTS}

This review is based on a previous review [1]. It is currently based on 349 papers, 274 more papers compared to its previous version in 2007 , which warrants the update.

*Address correspondence to this author at the Neurosurgical Associates, Red-Cross Hospital, Bergmannstraße 32, D-34121 Kassel, Germany;

Tel: (+49)-561-3163990; Fax: (+49)-561-3163992;

E-mail: keeflang@online.de

\section{Indications and Applications}

\section{Human}

PbtO2 monitoring technology is largely used in neurosurgical and neurologic intensive care. The majority of publications are based on analysis of data from adult patients suffering from severe traumatic brain injury (TBI), which indicates that this condition represents the largest field of clinical application [2-22]. It is also used in patients with multiple extracranial injuries and TBI, so called "polytraumatized patients" [23]. It is also used in children [24-40].

The second largest group of publications comprises aneurysmal subarachnoid hemorrhage (SAH) [6, 7, 41-59].

$\mathrm{PbtO} 2$ monitoring technology is also used intraoperatively during aneurysm surgery [45, 52, 60-64], during surgery of cerebral arterio-venous malformation $[60$, 65, 66], functional stereotaxy [67], and during cerebral angiography [68]. It has also been used in patients with spontaneous intraparenchymal hemorrhage [69-76], ischemic stroke in children and adults [36, 71, 77], severe haemorrhagic stroke [78], and in silent infarcts after subarachnoid hemorrhage [79].

\section{Case Reports}

A pbtO2 monitoring course during cardiopulmonary resuscitation [80], and a course of Vein of Labbe thrombosis [81] have been published as case reports. One case report presents the effects of high-dose inhaled aerosolized prostacyclin therapy for acute lung injury on cerebral 
oxygenation [82]. A case report describes a carotid dissection during angioplasty for cerebral vasospasm with pbtO2 monitoring in situ [43]. Hypoxic brain damage management after cardiac arrest in a child with catecholamine-induced cardiac arrhythmia using pbtO2 monitoring has been presented [29]. One paper reports on pbtO2 monitoring in 2 pediatric cases with tuberculous meningitis [31]. One paper reports its utility in a case where decompressive hemicraniectomy was guided by pbtO2 monitoring in a patient with bacterial meningitis [83], a similar case was reported in a patient after brain gunshot [84].

Other case reports include a patient with aneurysmal subarachnoid hemorrhage associated with aortic coarctation [85], status epilepticus-induced hyperemia and brain tissue hypoxia after cardiac arrest [76], and pulmonary embolus from acute superior sagittal sinus thrombosis secondary to skull fracture [86].

$\mathrm{PbtO} 2$ monitoring technology has also been used in brain tumor surgery $[71,73,87,88]$, and for continued postoperative monitoring in awake patients [89]. It has also been used for Normal Pressure Hydrocephalus management in awake patients $[90,91]$. One study reports that pbtO2 monitoring has been used in ventricular infusion studies on 33 patients suspected of idiopathic normal pressure hydrocephalus (iNPH), benign intracranial hypertension (BIH) or occlusive hydrocephalus (HOC) in order to confirm shunt indications [92].

It has also been used for diagnosis of idiopathic intracranial hypertension with measurements in an awake patient [93]. This case report is noteworthy because it demonstrates that the technology can be safely used in subjects undergoing physical exercise (running, cycling). It also demonstrated cortical hyperoxygenation in a human breathing natural air without oxygen supplementation [93]. Brain tissue oxygenation-guided management of diabetic ketoacidosis induced cerebral edema has also been reported in two paediatric cases [40]. One paper reports on "threshold-based brain oxygen monitoring for seizure detection" after SAH and TBI [94].

This technology has also been used to study the effects of anaesthetic agents $[95,96]$ as well as the effects of hypo and hyperthermia on cerebral oxygenation [97-99].

Last but not least pbtO2 monitoring has been subject to the "Development and validation of an integrated computational model of cerebral blood flow and oxygenation" with a subsequent report on "Modeling the causes of variation in brain tissue oxygenation" $[100,101]$.

\section{Animal}

The numbers of animal studies, which are designed to support and further investigate clinical pbtO2 applications in trauma, resuscitation models and the effects of various drugs have once again increased since the previous edition of this report [12, 23, 102-141]. It is used to measure oxygen delivery to brain parenchyma in animal models $[111,113$, $115,133,135,142-151]$. The utility in traumatic brain injury and severe uncontrolled haemorrhage with short delay prehospital resuscitation was examined in a swine model [152].
Animal models have also been used for comparative studies using different cerebral monitoring applications, e.g. near-infrared spectroscopy [153], ICP [154], muscle tissue oxygen, CBF [145], and cerebral microdialysis [155].

$\mathrm{PbtO} 2$ monitoring has also been used in animal models of spontaneous intracerebral hemorrhage [110, 156], malignant soft tissue tumors [157, 158], ischemic stroke [159], in experimental subarachnoid hemorrhage [160], in a swine model of pediatric traumatic brain injury [161], a rodent model of penetrating ballistic-like brain injury [162], in a rodent model of acclimation and deacclimation to hypoxia [163], in a standardized experimental brain death model [164], in experimental anhepatic liver failure [165, 166], an in potassium-induced cortical spreading depression [167].

One animal study reports on comparative monitoring with one Licox probe inserted into a glioblastoma multiforme [C6 glioma rat model] and a contralateral cerebral hemisphere [103].

It is also used in animal models to study cerebral oxygenation during postasphyxial seizures [116]; transfusion protocols [118], Erythropoitin administration [148], circulatory recovery [106], evoked neural stimulation [151], hibernation [105]; and cerebral blood flow, electrocorticographic activity after hypoxia [107]. PbtO2 measurements have also been performed in isolated rodent intestinal tissue with a special focus on "possible pitfalls in the interpretation of microcirculatory measurements" [168].

Spinal cord intraparenchymal and subdural CSF monitoring in a traumatic spinal cord injury model has been reported [169] and last but not least feasibility and various aspects of "a fully implantable telemetry system for the chronic monitoring of brain tissue oxygen in freely moving rats" have been published [170].

\section{Clinical Applications}

$\mathrm{PbtO} 2$ monitoring technology is increasingly used, which is reflected by a growing number of original publications. The majority of publications come [in alphabetical order] from Germany, Italy, Spain, The Netherlands, the UK, and the USA $[5-8,12-14,24,25,47,48,52,54,55,65,80,81$, $88,89,91,110,112,128,158,171-196,197,311]$.

There are publications also from Australia [38, 198-200], Austria [53, 85], Brazil [58], Canada [93, 118, 132, 135, 139], China [9, 201, 202], Croatia [203], the Czech Republic [204], Denmark [134]; Finland [134], France [43, 77, 114, 205, 206], Greece [207], Hungary [141], India [208], Japan [140, 146, 167, 209], Portugal [64]; Russia [210, 211], Singapore [2, 4, 10, 16, 74, 212, 213]; Serbia [214]; South Africa [26, 28, 35], South Korea [127], Sweden [90, 134, 215], Switzerland [11, 216, 217], and Taiwan [218].

$\mathrm{PbtO} 2$ monitoring is almost exclusively used in combination with other cerebral non-invasive and invasive monitoring modalities, in particular intracranial pressure [ICP] monitoring $[4,6,17,22,24,26,32,33,50,51,53,55$, 72, 81, 88 202, 91, 130, 176, 187, 203, 206, 219-223], cerebral perfusion pressure (CPP) monitoring $[3,4,10,25$, $178,187,198,224-226]$, jugular venous saturation (JvDO2) monitoring [184, 190, 206, 227, 228], cerebral microdialysis $[17,74,83,114,117,186,193,196,205,207,212,227$, 229-238], cerebro spinal fluid (CSF) chemistry [239], 
cerebral blood flow velocity (CBFV) measured by transcranial Doppler ultrasound (TCD) $[8,30,88$ 202, 178, 237], regional cerebral blood flow measurements (rCBF) $[47,240-242]$, near infrared spectroscopy (NIRS) $[15,123$, $179,190,243]$, intracranial temperature measurements $[9$, 97, 99, 141], oxygen-15 positron emission tomography (15O-PET) [230], continuous surface electroencephalogram [94], and cortical spreading depolarizations (CSD) monitoring using subdural electrocorticography $(\mathrm{ECoG})$ strip electrodes [244].

\section{Oxygen Monitoring Technologies}

Six monitoring devices are found in the literature, "Licox", "Neurotrend", "Neurovent-PTO", "MPBS", "Foxy AL-300", and a probe called "PO2-100DW".

Licox is manufactured by GMS-Integra, (KielMielkendorf, Germany). Neurotrend is manufactured by Codman, Johnson \& Johnson (Raynham, MA, USA). Neurovent is manufactured by Raumedic (Münchberg, Germany). MPBS is manufactured by Oxford Optronix [Oxford, UK]. Foxy AL-300 is manufactured by Ocean Optics (Dunedin, FL, USA). The "PO2-100DW" is manufactured by Inter Medical Co. Ltd. (Nagoya, Japan).

The Neurotrend probe uses optical sensors. Measurements are obtained through a dye which is connected to a fiberoptic cable. The properties of the dye change along with gas concentrations and $\mathrm{pH}$ of adjacent tissues, which in turn reflects tissue partial pressure of oxygen. The Neurotrend probe contains four sensors, it measures pbtO2, ptiCO2, tissue $\mathrm{pH}$, and tissue temperature. Its sampling area is around $2 \mathrm{~mm}^{2}$.

The Licox probe uses a polarographic ("Clark") cell in which oxygen diffuses from the tissue through the catheter polyethylene wall into its inner electrolyte chamber. Oxygen is transformed at the electrode where it determines an electrical current. The electrical current reflects tissue pbtO2. Its sampling area, depending of the type of oxygen sensor, is around $13 \mathrm{~mm}^{2}$ to $18 \mathrm{~mm}^{2}$.

The Neurotrend probe yields lower values compared to the Licox probe. This is a difference due to the probe's monitoring techniques, which users must be aware of. It does not indicate measurement validity.

The "Neurovent-PTO" is a sensor which measures pbtO2, ICP and brain temperature. The pbtO2 measurement principle is based on exciting a flourescent dye with light. $\mathrm{PbtO} 2$ is calculated from the fading properties of the fluorescent dye, so called "luminescense quenching". Its sampling area is around $22 \mathrm{~mm}^{2}$ [71].

The Oxford Optronix and the Foxy-ptiO2 sensor also use the "luminescense quenching" technique. The Oxford Optronix sensor, referred to as "multi-parametric brain sensor" [MPBS] also measures laser-Doppler based cerebral blood flow and ICP $[149,245]$. It is a prototype and has been used in animals [246]. The Foxy AL-300 has also been used in animals [247].

The "PO2-100DW" is a micro polarographic cell sensor (Clark type electrode) and has been used in an animal study [167].

\section{Catheter Placement and Sampling Size}

Catheters are generally placed in the right frontal lobe white matter in diffuse brain injury or for detecting global ischemia, or on the affected side in a hemispheric injury and by and at large remain in situ for as long as ICP measurements are required [197, 206, 229, 248-252]. During intraoperative aneurysm surgery and ICU treatment probe placement in the territory of the aneurysm harboring vessel has been advocated $[44,62,63]$. As expected pbtO2 is lower in peri-contusional tissue than in normal appearing tissue on CT scanning in TBI patients [253]. Some groups, however, prefer measurements contralateral to the side of mass lesions $[18,39]$.

A run-in time of approximately 1 to 2 hours is required before valid measurements are available and a short oxygen challenge is useful to test proper performance $[13,67,172$, 197, 254]. In some cases the run-in time may be shorter or longer. We feel that a sensible approach is to wait until stable monitoring values show up on the monitor.

One paper has further investigated the effect of catheter location on the relationship between pbtO2 and neurological outcome in severe TBI. They report that: "When the pbtO2 probe was placed in abnormal brain, the average pbtO2 was higher in those with a favorable outcome, $28.8+/-12.0 \mathrm{~mm}$ $\mathrm{Hg}$, compared with those with an unfavorable outcome, 19.5 $+/-13.7 \mathrm{~mm} \mathrm{Hg}(\mathrm{P}=.01) . \mathrm{PbtO}_{2}$ and outcome were not related when the probe was placed in normal-appearing brain". They conclude that ...the location of the pbtO2 probe determines the $\mathrm{pbtO} 2$ values and the relationship of pbtO2 to neurological outcome" [252]. This may account for various pbtO2 cutoffs and thesholds which have been reported, e.g. $16 \mathrm{mmHg}$ [314], or $29 \mathrm{~mm} \mathrm{Hg}$ [255].

Although it is a local measurement, restricted to a small cerebral volume, its utility to reflect hemispheric conditions has been demonstrated in studies where pbtO2 measurements were correlated with cerebral arteriovenous oxygen difference [AVDO2] and cerebral blood flow (CBF) measurements. Not only did they show a strong correlation but they also showed that pbtO2 measurements did pick up more ischemic events than the global measurement [120, $122,256]$. PbtO2 monitoring is also a rather sensitive marker for cerebral ischemia, which "....allows for early recognition of low O2 delivery, enabling appropriate therapeutic intervention" [24]. This finding is supported in a comparative study which confirmed a correlation between $\mathrm{CBF}$ and pbtO2: "The level of pbtO2 seems to be predominately determined by regional $\mathrm{CBF}$, since changes in pbtO2 were correlated in $90 \%$ of episodes to simultaneous changes of CBF" [47]. Further evidence to support the fact that $\mathrm{CBF}$ is a strong determinant of pbtO2 is suppplied in a study where $\mathrm{O} 2$ reactivity was determined at various levels of rCBF. It showed a significant correlation between CBF and $\mathrm{O} 2$ reactivity [240]. An observational study where pbtO2 was recorded during surgery of incidental MCA aneurysms reports that: "pbtO2 monitoring during aneurysm surgery shows brain tissue perfusion in real time and there is a correlation between any episode of reduced blood flow to the affected vascular territory during surgery and a decrease of pbtO2 value [63]. A case report in a patient who developed seizures following CPR after a cardiac arrest showed dramatic pbtO2 decreases along with large $\mathrm{CBF}$ 
surges, which the authors interpret as: "...increased metabolic demand out of proportion to CBF increase" [76].

The metabolic heterogeneity of different tissue types is well known because it affects sampling size considerations. It is important to factor in the heterogeneous nature of the brain when interpreting oximetry data. Early experiments on rats have demonstrated the differing pbtO2 within the cortex depend of the depth of probe placement [257]. This has also been shown in an early human study [13]. It was proposed that the differing base levels relate to the metabolism, microcirculation and overall microstructure of each environment. Furthermore, depending on the probes relationship to the arterial micro-vessels, a gradient within the tissues can exist with oxygen levels decreasing over the space from arterial to venous circulation. The microenvironment is influenced by the cerebral blood flow velocity of each microenvironment, with low velocities showing the highest variability in terms of oxygenation differences [121]. This translates into a situation where spatial heterogeneity must be compensated for by a sufficiently large sensor sampling area to minimize the so called "random position error". This random position error will yield pbtO2 levels anywhere from 15 to $40 \mathrm{mmHg}$ if the $\mathrm{O} 2$ sensitive area is limited to $1,4 \mathrm{~mm}$ in length. If the area is increased to $5,0 \mathrm{~mm}$ the range is reduced to values between 25 and $30 \mathrm{mmHg}$ [121].

\section{Impact on Clinical Situations and Treatment Strategies}

There are numerous and, from a scientific/research as well as clinical/treatment point of view, most interesting findings which have derived from about 15 years of research using pbtO2 technology. The following paragraphs summarize the important ones:

\section{Definition of Normal and Pathological Values - A Complex Task}

Normal pbtO2 values based on Licox technology are around 25 to $30 \mathrm{mmHg}$, based on animal research [119]. This was confirmed in patients with normal ICP and CPP [13, 256].

Functional stereotaxy operations for movement disorders with Licox based pbtO2 measurements in normal white matter have confirmed these values. The authors report 22.6 $\pm 7.2 \mathrm{~mm} \mathrm{Hg}$ for frontal white matter intraoperative recordings during local anaesthesia. These measurements were confirmed during a 24-hour postoperative continued measurement with values of $23.1 \pm 6.6 \mathrm{~mm} \mathrm{Hg}$ [67]. In addition, at optimal vascular reactivity in 27 TBI patients, pbtO2 was $24.6+/-6.0 \mathrm{mmHg}$ [258].

One group has investigated the relationship between markers of ischemia from cerebral microdialysis and an ischemic pbtO2 threshold below $20 \mathrm{mmHg}$ in $\mathrm{SAH}$ patients. They report that: "Mortality was associated with increased percentage of samples with elevated lactate and brain hypoxia $28 \%$ (interquartile range $9 \%-95 \%$ ) in nonsurvivors". This study supports the current clinical practise that pbtO2 below $20 \mathrm{mmHg}$ signals cerebral ischemia and may call for therapeutic interventions [217].

Normal pbtO2 value in children may be higher than in adults. One paper suggests that $30 \mathrm{mmHg}$ may be normal in children based on their finding that a pbtO2 of $30 \mathrm{~mm} \mathrm{Hg}$ was associated with the highest sensitivity/specificity for favorable neurological outcome at 6 months after TBI [39]. It must be noted, however, that they measured pbtO2 in the uninjured frontal cortex. They emphasize that: "CPP was the only factor that was independently associated with favorable outcome. Surprisingly, instances of preserved pbtO2 with altered ICP and CPP were observed in some children with unfavorable outcomes [39].

Normal pbtO2 values based on Neurotrend technology are lower [259], a paper has suggested a threshold of $14 \mathrm{mmHg}$ [260].

A one-on-one direct intraparenchymal comparison between Licox and Neurovent in 33 patients showed no relevant differences between the Licox $(19.5 \pm 7.1 \mathrm{mmHg})$ and Neurovent multiparameter probe derived values $(21.7 \pm 9.5 \mathrm{mmHg})$ [71]. This was not confirmed in a preliminary report in 11 mixed TBI and SAH patients [261]. They increased MAP by $20 \mathrm{mmHg}$ for $10 \mathrm{~min}$ and varied $\mathrm{FiO} 2$ and they report that pbtO2 differed significantly at all times. "The Licox probe reacted significantly faster to changes in $\mathrm{FiO}(2)$ and MAP. Limits of agreement ranged between -32.1 and $20.0 \mathrm{mmHg}$. Mean Licox values were 6.1 mmHg lower than Neurovent values". They conclude that: "These data therefore do not support the view that both probes can be used interchangeably" [261].

Based on analysis of ischemia markers from cerebral micodialysis a critical ischemic threshold below $10 \mathrm{mmHg}$ has been reported in an animal study, in which the Neurovent-PTO probe was used [262]. Some clinicians consider $7 \mathrm{mmHg}$ as the critical ischemic threshold [92]. One study reports on the signifiicant association between serum levels of S100beta, neuron-specific enolase, and glial fibrillary acidic protein, which are considered serum biomarkers in severe TBI patients, and hypoxia measured by pbtO2 prior to the onset of clinical symptoms [263].

The "Guidelines for the management of severe traumatic brain injury" issue a Level III recommendation for pbtO2 monitoring and recommend maintaining pbtO2 $>15 \mathrm{mmHg}$ [264].

A study published in 1998 demonstrated that the likelihood of death increased with increasing duration of time at or below a pbtO2 of 15 torr $(2.0 \mathrm{kPa})$ or with the occurrence of any pbtO 2 values of $<$ or $=6$ torr $(<$ or $=0.8$ $\mathrm{kPa}$ ) [265]. This is supported by an analysis of 103 TBI patients in which the authors conclude that "... Brain hypoxia is associated with poor short-term outcome after severe traumatic brain injury independently of elevated ICP, low $\mathrm{CPP}$, and injury severity. Other than ICP and CPP, pbtO2 is an independent factor for outcome [266]. One paper has pointed out that initial radiographic and clinical scales, which are correlated with patient outcome after TBI, are not associated with subsequent ICP or pbtO2 [267]. PbtO2 may be an important therapeutic target after severe traumatic brain injury [268].

These studies have also helped to establish a generally accepted treatment threshold, which has been confirmed by other papers although no clear cut-off value can be given for both TBI and SAH [56, 172]. Similar results have been reported for pediatric TBI and it has been stressed that: "...many patients experience episodes of compromised 
pbtO2 despite achieving acceptable treatment targets." [28], and "...low brain oxygen levels during the first $24 \mathrm{~h}$ following head injury may not correlate necessarily with poor outcome [27]. Formal analysis of outcome prediction variables has shown that: "The combined use of microdialysis variables and pbtO2, in addition to ICP, MAP, and CPP was found have the best predictive accuracy" [250].

Of interest is another paper that has reported that "The presence of anaerobic cerebral metabolism probably depends on duration and severity of the hypoxic episode" [232]. This conclusion is relevant for clinical practise because it shows that: $a$. pbtO2 monitoring technology detects short episodes of cerebral hypoxia which are not picked up by other monitoring modalities $b$. magnitude and duration of cerebral hypoxia have prognostic relevance. One study also reports on the positive correlation and prognostic value of pbtO2 measurements and longterm neuropsychological outcome after severe traumatic brain injury [269].

This section shows that various factors contribute for the different thresholds described above. Several others can be listed: age (paediatric, adult), co-morbidity, injury severeity (GCS, ISS, etc), underlying pathology (see list of indications), timing of placement (pre-, intra-, post OP, secondary deterioration), catheter location (injured $v s$ noninjured side, catheter location if monitored in the injured side, i.e. healthy tissue, penumbra zone, injury area), data acquisition frequency (minutely, hourly), therapeutic interventions [see below], time of outcome assessment [discharge, 3 months, 6 months], outcome measures (GOS, neuropsychological measures, etc.).

\section{The Problem of the Randomized Controlled Trial [RCT]}

Up to date there is no RCT (class one evidence) which has shown outcome improvement with pbtO2 monitoring. Four controlled reports are available [226, 270-272]. All other papers are uncontrolled or case reports. Consequently the "Guidelines for the management of severe traumatic brain injury" issue a Level III recommendation for pbtO2 monitoring [264]. The frequently proposed RCT is under way. It is called "Brain tissue oxygen monitoring in traumatic brain injury (TBI)" (BOOST 2), and can be found at: http://clinicaltrials.gov/ct2/show/NCT00974259. It started in October 2009 and it is scheduled to be finish in August 2014. No preliminary results are yet available.

In a series of 53 TBI patients 25 patients were treated using an ICP monitor alone while 28 patients had pbtO2directed care, with comparable ICP and CPP levels for each group [226]. The mortality rate was $44 \%$ for the first group, $25 \%$ for the second group, which was statistically significant. Although they were not exactly matched for age, $44 \pm 14$ years for the ICP/CPP group vs $38 \pm 18$ years for the pbtO2 group, the outcome difference was significant $[p<$ 0.05]. The conclude that "The use of both ICP and brain tissue PO2 monitors and therapy directed at brain tissue PO2 is associated with reduced patient death following severe TBI" [226]. This report on outcome was not confirmed in a larger, uncontrolled series [22]. The authors report that a pbtO2 guided treatment supplementing ICP/CPP therapy did not result in improved outcome at six months, despite a significant reduction in cerebral hypoxic episodes.
An outcome study of 145 TBI patients receiving either ICP or Licox-pbtO2 monitoring reports that mortality, hospital length of stay, and ICU length of stay were equivalent. More patients in the Licox group achieved a moderate/recovered GOS at 3 months than in the Camino Group $(79 \%$ vs $61 \% ; \mathrm{P}=.09)$. Six-month outcomes were also better although not at a statistically significant level [271].

One study confirms that an ICP/pbtO2 directed protocol reduces the mortality rate after $\mathrm{TBI}$ in major trauma and resulted in improved 6-month clinical outcomes over the standard ICP/CPP-directed therapy when compared to historical controls [270].

One paper, which was published in 2009 deserves special attention: This series has not confirmed the utility of pbtO2 monitoring for TBI patients [272]. The authors report that: [1] The mortality rate in 123 patients with traumatic brain injury whose clinical management was guided by pbtO2 monitoring was not reduced in comparison with that in patients who received ICP monitoring alone, and [2]. Brain tissue oxygen monitoring was associated with worse neurological outcome and increased hospital resource utilization [272]. In consideration of the possible implications of their findings the authors seek to find reasons for their findings. They report that the pbtO2 monitored group was younger and more severely injured. They argue that their treatment threshold of $20 \mathrm{mmHg}$ may have been incorrect and that that treatment strategies, e.g. CPP augmentation using vasopressors may have caused more harmful side effects than beneficial effects. At last they argue that the potential for residual confounding is most likely due to the observational nature of their study with a lack of proper randomization. The authors conclude that a randomized trial is necessary to address the issue. This is in keeping with the arguments previously listed [200, 273].

\section{PbtO2 and Other Monitoring Parameters}

An analysis of a large pediatric TBI series has suggested that pbtO2 cannot be inferred from other clinical and physiological variables. The authors stress that: "Reduced pbtO2 is shown to be an independent factor associated with poor outcome in pediatric severe TBI in the largest study to date. It appears to have a stronger association with outcome than conventionally evaluated measures [33]. They continue to conclude that: "Our data show that pbtO2 is poorly predicted by clinical and physiological factors commonly measured in the pediatric ICU. Multimodality monitoring may be needed to detect all secondary cerebral insults in pediatric TBI after TBI" [32].

The same group also studied the frequency of an adverse event, defined as a pbtO2 of less than $10 \mathrm{mmHg}$, as a point prevalence at 24 and $72 \mathrm{~h}$ post-injury, compared with the cumulative burden measured as a frequency of the event over the full duration of monitoring They report that: "Reduced pbtO2 was more common early than late after injury. The point prevalence of reduced pbtO2 at the selected time points was relatively low [10\% of patients at $24 \mathrm{~h}$ and no patients at the 72-h mark post-injury]. The cumulative burden of these events over the full duration of monitoring was relatively high: $50 \%$ of patients had episodes of pbtO2 less than $10 \mathrm{mmHg}$ and $88 \%$ had $\mathrm{PbtO} 2$ less than $20 \mathrm{mmHg}$ ". 
They conclude that: "Point-in-time monitoring in a dynamic condition like TBI may underestimate the overall frequency of adverse events, like reduced $\mathrm{pbtO}_{2} \ldots$ " It supports the utility of continuous rather than hourly monitoring and recording/charting [37].

\section{Treatment Stategies}

When it comes to treating reduced ptiO2 "the nature and effectiveness of commonly used interventions in correcting compromised pbtO2 in TBI remains unclear" [274]. In an attempt to evaluate the effectiveness and magnitude of interventions the authors report their retrospective review of a series of 92 TBI patients, in which they report that: "Five interventions: narcotics or sedation, pressors, repositioning, FIO2/PEEP increases, and combined sedation or narcotics and pressors were the most commonly used strategies. Increasing the number of interventions resulted in worsening the time to pbtO2 correction. Triple combinations resulted in the lowest DeltaICP and dual combinations in the highest DeltaCPP $(p<0.05)$ [274]. They conclude that: "Clinicians use a limited number of interventions when correcting compromised pbtO2. Using strategies employing many interventions administered closely together may be less effective in correcting pbtO2, ICP, and CPP deficits. Some pbtO2 deficits may be self-limited" [274].

$\mathrm{PbtO} 2$ monitoring has been used to study the effects of the neurological wake-up test with interruption of sedation and analgesics (IS) [229]. The authors report that: "In IStrials that had to be aborted, a significant increase in ICP and decrease in pbtO2 $(\mathrm{P}<0.05)$, including $67 \%$ with critical values of pbtO $2<20 \mathrm{mmHg}$, a tendency to brain metabolic distress $(\mathrm{P}<0.07)$ was observed" [229].

\section{Hyperventilation}

Several studies have addressed a long and much debated issue in neurocritical care: the role of hyperventilation for controlling intracranial hypertension. Hyperventilation constricts cerebral blood vessels which will lead to ICP reduction, however in turn can cause reduced $\mathrm{rCBF}$, hypoperfusion and ischemia and lead to exacerbation of brain swelling. PbtO2 technology has the potential to guide the degree of hyperventilation because of its ability to indicate states of hypoperfusion and impending ischemia $[70,102,112,175,241,275,276]$.

This utility has also been demonstrated intraoperatively in AVM surgery: "PbtO2 monitoring has a high reliability in the detection of intraoperative tissue hypoxia" [65]. Similar recommendations have yet previously been reported [183]. One paper, however reports that in 3 of 17 TBI patients they noted an increase of pbtO2 on hyperventilation, which they called a "paradox reaction" [277]. This pattern was only seen in the early phase between days 0 and 3 after injury. It may represent flow-metabolic uncoupling, and it stresses the utility of multimodality monitoring for which other parameters are used as well.

\section{Aneurysm Surgery - Intraoperative Utility}

One paper adresses the utility of intraoperative pbtO2 recording during MCA aneurysm surgery after SAH and the authors suggest that surgical action may be revised if pbtO2 decreases. They report that: "Postoperative infarction in the territory of MCA developed in cases with an abrupt decrease of pbtO2 and a very low and persistent minimum value, during temporary clipping, and an incomplete recovery after definitive clipping. Verification of clip position should be considered when there is an incomplete recovery or a persistent fall in pbtO2 after definitive clipping“ [62]. The same group has also published on the same matter for surgery of unruptured MCA aneurysms. Here they report that: "PbtO2 monitoring during aneurysm surgery shows brain tissue perfusion in real time and there is a correlation between any episode of reduced blood flow to the affected vascular territory during surgery and a decrease of pbtO2 values. Unexpected low basal values were obtained in "uninjured" brain, with no influence from subarachnoid hemorrhage. The values of risk for brain infarction during temporary arterial occlusion still need further studies, but an incomplete recovery or a persistent fall in pbtO2 values after definitive clipping should be considered as an indication for verification of the position of the clip [63].

\section{Triple H Therapy}

$\mathrm{PbtO} 2$ technology has been used to investigate the utility of hypervolemia and hypertension therapy for prophylaxis and treatment of symptomatic cerebral vasospasm in $\mathrm{SAH}$ [278]. The authors, most interestingly, report that during 55 periods of moderate hypertension pbtO2 increases were found in 50 cases $(90 \%)$, with complications occurring in three patients $(8 \%)$. During 25 periods of hypervolemia, pbtO2 increases occurred during three intervals (12\%), with complications occurring in nine patients $(53 \%)$. During the 10 periods of aggressive hypervolemic hypertension, pbtO2 increases were found during six of the intervals $(60 \%)$, with complications in five patients $(50 \%)$. They concluded that "in poor-grade patients, moderate hypertension (CPP 80-120 $\mathrm{mm} \mathrm{Hg}$ ) in a normovolemic, hemodiluted patient is an effective method of improving cerebral oxygenation and is associated with a lower complication rate compared with hypervolemia or aggressive hypertension therapy". A similar conclusion has been reported from another group [55]. Both reports support the utility of pbtO2 for optimizing Triple-HTherapy in SAH patients.

\section{Vasospasm Detection After SAH}

The utility of pbtO2 monitoring in cerebral vasospasm afer SAH is subject of three reports [279-281]. The first study reports that post-operative TCD vasospasm developed in 13 patients, all of which had intraoperative pre-clipping pbtO $2<10 \mathrm{mmHg}$ and pbtO2 was significantly lower in cases that developed TCD vasospasm. This association was independent of age, clinical status, or CT findings. The authors conclude that: "The finding of low intraoperative basal pbtO2 values may be an indicator for a high risk of occurrence of post-operative TCD vasospasm in cases of aneurysmatic SAH" [279]. The second study reports a significant pbtO2 increase in a series of vasospasm patients after endovascular treatment while CPP, ICP, $\mathrm{SaO}(2)$, and $\mathrm{FiO}_{2}$, did not. They conclude that: "pbtO2 monitoring provides the interventionalist with an objective physiologic parameter to determine adequate spasmolysis" but point out that: "Further investigation is needed to establish target pbtO2 rates indicative of adequate reperfusion, which can be used in the endovascular suite" [280]. The third study reports 
that Erythropoietin increases pbtO2 in severe $\mathrm{SAH}$ patients with severe cerebral vasospasm but they point out that the effect on outcome requires further investigation [281].

One interesting case report presents a patient suffering from delayed and profound post-traumatic vasospasm, which was recognized solely by pbtO2 monitoring. The patient was successful treated with intraarterial Verapamil and baloon angioplasty [57].

\section{Head and Body Position}

$\mathrm{PbtO} 2$ technology has been used to address another much and long debated issue in neurocritical care: the role of head elevation. A study in 2004 using pbtO2 measurements has demonstrated that "Routine nursing of patients with severe head injury at 30 degrees of head elevation within 24 hours after trauma leads to a consistent reduction of ICP [statistically significant] and an improvement in CPP [although not statistically significant] without concomitant deleterious changes in cerebral oxygenation" [10]. The effects of various other changes of head and body positions on pbtO2 has been reported and the authors conclude that: "Positioning practices can positively or negatively affect pbtO2 and ICP and fluctuate with considerable variability among patients. Nurses must consider potential effects of turning, evaluate changes with positioning on the basis of monitoring feedback from multimodality devices, and make independent clinical judgments about optimal positions to maintain or improve cerebral oxygenation" [282].

$\mathrm{PbtO} 2$ technology has been used to assess the effects of prone position on CPP and pbtO2 in SAH patients with acute respiratory distress syndrome (ARDS) [53]. The authors report a beneficial effect of prone positioning on pbtO2 by increasing arterial oxygenation. This effect outweighs the adverse effect of prone positioning on cerebral tissue oxygenation by decreasing cerebral perfusion pressure in ARDS patients.

\section{PbtO2 during Patient Transport}

Directions, magnitudes, and time courses of patient transport for $\mathrm{CT}$ scanning on pbtO2 has been systematically assessed [283]. The authors conclude that: "... transport to and from the intensive care unit may adversely affect pbtO2. This deleterious effect is greater when pbtO2 is already compromised and may be associated with lung function." Fifty-seven CT scans in 34 TBI patients using a portable scanner without patient transport had no effects on pbtO2 [284].

\section{Decompressive Craniectomy and Ventricular Drainage}

It has been shown in TBI and SAH patients that decompressive craniectomy improves pbtO2 [212, 285]. Three papers have addressed the utility of pbtO2 monitoring technology for timing of decompressive hemicraniectomy (DCH) in severe brain swelling [7, 42, 221]. One case report addresses its utility for DCH in a patient suffering from bacterial meningitis [83]. It has been shown that not only absolute pbtO2 values should be considered for the indication of DCH but also magnitude and the time course of monitoring trends [7]. Another study has concluded that " ...pbtO2 monitoring could be an important tool for timing craniectomy in the future" [221]. This report is supported by a case report [205]. The effects of DCH, which represents a very invasive treatment option and which is considered an ultimate surgical treatment option has also been studied: "DCH in the treatment of severe brain injury is associated with a significant improvement in brain oxygenation" [6]. In another, however small, series of patients it was pointed out that despite a rapid pbtO2 increase and ICP reduction from critical to normal values "the patients' clinical status remained poor with two in a persistent vegetative state and one dead" [50]. This is in keeping with the long-standing and unresolved debate about the utility of DCH and its particular regard to outcome [286].

It has also been reported that ventriculostomy for control of intracranial hypertension in TBI leads to a significant pbtO2 improvement, irrespective of the pre-procedural pbtO2 level [287].

\section{Nimodipine, Mannitol and Hypertonic Saline Solution}

Other long and much debated issues in neurocritical care have been addressed under consideration of pbtO2 measurements: the effects of commonly used drugs in neurocritical care: Nimodipine and Mannitol. A paper published in 2005 has reported that "... although Nimodipine use is associated with improved outcome following $\mathrm{SAH}$, in some patients it can temporarily reduce brain tissue PO2" [51]. A pbtO2 increase following intraarterial Nimodipine infusion was reported in 8 out of 9 SAH patients with refractory arterial vasospasm [288]. These reports will spark the academic discussion about whether Nimodipine should be used in patients suffering from aneurysmal subarachnoid hemorrhage. The most valuable conclusion for daily neurocritical care practise which can be extracted from this study is that using pbtO2 monitoring technology will identifiy those patients in which Nimodipine has a negative effect [176].

In this context it can be noted that Nicardipine, when used to treat acute hypertensive emergencies in a combined aneurysmal SAH, ICH, AVM, and hypoxic brain injury series, had no effect on pbtO2, despite significant CPP reduction [289].

With regard to Mannitol it has been shown that although Mannitol reduces ICP it has little effect on pbtO2 [17, 176]. This is rather unexpected because it is expected that ICP reduction will improve pbtO2. The important clinical conclusion from this finding - however is that pbtO2 monitoring technology should be used in addition to ICP monitoring as the two monitoring parameters are not ultimately linked. Further evidence to support this finding is provided in a series of 12 patients after severe haemorrhagic stroke [78]. The authors report that: “...CPP increased 45 $\min$ [from $73+/-18$ to $85+/-22 \mathrm{~mm} \mathrm{Hg}, \mathrm{p}=0.002$ ] after the start of mannitol infusions, whereas mean arterial blood pressure and pbtO2did not change significantly [78]".

The effects of hypertonic saline solution [HSS] on pbtO2 have been studied in 12 hypotensive patients after severe TBI [220]. The authors report a uniform and persistent pbtO2 increase, along with a $45 \%$ ICP decrease, which lasted for six hours, a subsequent CPP increase, and less demand for inotrope use [220]. Similar results have been reported elsewhere $[44,219,290]$, although the persistent pbtO2 increase has not been confirmed in a combined TBI 
and stroke series in which Mannitol and HSS were compared [77]. This may be due to different treatment thresholds and different time points for post infusion assessment of monitored variables in different series [290].

\section{Vasopressors}

Vasopressors are commonly used in neurocritical care. There is debate whether Dopamine or Noradrenaline should be preferred. $\mathrm{PbtO} 2$ monitoring has been used to study the effects of both drugs in a comparative studies. The authors report that: “... CPP augmentation with norepinephrine, but not with dopamine, resulted in a significant reduction in arterial-venous oxygen difference $(37 \pm 11$ vs $33 \pm 12 \mathrm{ml} / \mathrm{l})$ and a significant increase in brain tissue oxygen $(2.6 \pm 1.1 \mathrm{vs}$ $3.0 \pm 1.1 \mathrm{kPa})$. The CPP intervention did not significantly affect intracranial pressure. There were no significant differences between norepinephrine and dopamine on cerebral oxygenation or metabolism either at baseline or following a CPP intervention; however, the response to a CPP intervention with dopamine seemed to be more variable than the response achieved with norepinephrine" [225]. Phenylephrine doubled pbtO2 in four of five TBI patients three hours after start of the infusion [228].

One animal study suggests adverse effects of Epinephrine on pbtO2 during CPR [291]. It must be said, however, that measurements were not clearly intraparenchymally and they used an optical sensor which is used for arterial blood gas analysis.

\section{Barbiturates and Sedatives}

The effect of barbiturates on pbtO2 has been studied in patients with refractory intracranial hypertension [2, 292]. One report concludes that "Of eight patients with prebarbiturate $\mathrm{PTiO}$ [2] levels above $10 \mathrm{mmHg}$, six had a further improvement in oxygenation" [2]. Obviously barbiturate therapy does not always lead to a pbtO2 improvement. This finding has also been reported in a series of 10 patients. The authors report that two patients experienced a significant pbtO2 decrease upon pentobarbital treatment [292].

The effects of a commonly used sedative in neurocritical care, propofol, have also been studies using pbtO2 monitoring. Somewhat unexpectedly they found that burst suppression induced by propofol has no effect on cerebral oxygenation [96]. An intraoperative bolus of dexmedetomidine in patients undergoing neurovascular surgery also had no effect on pbtO2 [60].

\section{Blood Glucose Levels and Obesity}

The issue of blood glucose levels and its relation to cerebral oxygenation in primary basal ganglia hemorrhage has been studied. The results show that a strict control of blood glucose levels $(4-8 \mathrm{mmol} / \mathrm{L})$ with continuous titrated insulin therapy is associated with improved cerebral oxygenation when compared to a conventional "sliding scale" ( 8.1 to $10 \mathrm{mmol} / \mathrm{L})$ bolus subcutaneous insulin administration [74].

It has also been reported that obesity is an independent predictor of compromised pbtO2. The authors speculate that this may be mediated through obesity-related pulmonary dysfunction and inadequate compensatory mechanisms [293].

\section{Fraction of Inspired Oxygen/Hyperoxia}

The fraction of inspired oxygen (FiO2) obviously affects cerebral pbtO2 levels. One study has recently addressed this issue, which is important in the interpretation of measured pbtO2 values [294]. The authors report a pbtO2 increase from a baseline of $30 \pm 5 \mathrm{mmHg}$ to $147 \pm 36 \mathrm{mmHg}$ when the $\mathrm{FiO} 2$ was increased from individual baseline values to $100 \%$. When it was decreased to $0.6 \mathrm{FiO} 2$ pbtO2 fell to $63 \pm 6$ $\mathrm{mmHg}$. Further evidence into the effects of FiO2 levels on pbtO2 is provided by a study which shows that the magnitude of pbtO2 changes depends on $\mathrm{rCBF}$ [240]. It has also been shown that 2-hour periods of normobaric hyperoxia $(\mathrm{NH})$ increases pbtO2 values but do not produce oxidative stress and/or change antioxidant reserves in CSF (lipid peroxidation (F2-isoprostane (ELISA)), protein oxidation [protein sulfhydryl (fluorescence)) and antioxidant defenses (total antioxidant reserve (AOR) (chemiluminescence) and glutathione (fluorescence)) [239]. Another paper in 30 TBI patients reports that $\mathrm{NH}$ “...increased $\mathrm{PaO}(2)$ and $\mathrm{PtiO}(2)$ and significantly decreased the lactate pyruvate ration in patients in whom baseline brain lactate levels were increased, suggesting that $\mathrm{NH}$ improved the brain redox state", and theyconclude that $\mathrm{NH}$ "... may only be effective in a specific group of patients" [197].

The issue of $\mathrm{O} 2$ reactivity in response to increased $\mathrm{FiO} 2$ levels has been studied in 37 TBI patients [194]. The authors measured $\mathrm{paO} 2$ and pbtO2 after an increase in $\mathrm{FiO} 2$ concentration from baseline to 1.0 for 20 minutes and created the "PF ratio". Patients with higher PF ratios achieved greater pbtO2 during oxygen challenge than those with a low PF ratio because they achieved a higher $\mathrm{PaO} 2$ after an oxygen challenge. They concluded that:"... lung function must be considered when interpreting brain tissue oxygenation" [194]. Using pbtO2 monitoring and the O2 reactivity in response to $\mathrm{FiO} 2$ variations one groups has reported that: "Acute lung injury is an independent risk factor for brain hypoxia after severe traumatic brain injury." [21]. They advocate: " the use of lung-protective strategies to prevent brain hypoxia in TBI patients."

The effects were also studied in a series of 28 children with severe TBI [34]. The authors conclude that: "Normobaric hyperoxia increases pbtO2 in children with severe TBI, but the response is variable. The magnitude of this response is related to the change in $\mathrm{PaO} 2$ and the baseline pbtO2. A greater response appears to be associated with worse outcome."

A study of 52 TBI patients showed that normobaric hyperoxia treatment resulted in a significant improvement in biochemical cerebral markers [295]. Using silmultaneous cerebral microdialysis they report increased glucose levels with significantly decreased glutamate and lactate levels. They also report lactate/glucose and lactate/pyruvate ratio decreases at comparable CPP levels. Outcome in the normobaric hyperoxia treatment group was improved. They concluded that: "...normobaric hyperoxia in patients with severe TBI improves the indices of brain oxidative metabolism. Based on these data further mechanistic studies and a prospective randomized controlled trial are warranted" 
[295]. Similar findings have been reported in a series of 8 TBI patients [193]. Another normobaric hyperoxia protocol was used in a study of 11 TBI patients, pbtO2 measurements were supplemented by cerebral microdialysis and oxygen- 15 positron emission tomography [230]. The authors conclude that: "...hyperoxia increases pbtO2 with a variable effect on lactate and lactate/pyruvate ratio. Microdialysis does not, however, predict the universal increases in cerebral metabolic rate of oxygen in at-risk tissue, which imply preferential metabolic benefit with hyperoxia".

The effects of hyperbaric and normobaric hyperoxia $[\mathrm{NBH}]$ were assessed in a prospective, randomized clinical trial in a series of 69 severe TBI patients [296]. The authors conclude that: "Hyperbaric $\mathrm{O} 2$ has a more robust posttreatment effect than NBH on oxidative cerebral metabolism related to its ability to produce a brain tissue $\mathrm{PO} 2>$ or $=200 \mathrm{~mm} \mathrm{Hg}$. However, it appears that $\mathrm{O} 2$ treatment for severe TBI is not an all or nothing phenomenon but represents a graduated effect. No signs of pulmonary or cerebral $\mathrm{O} 2$ toxicity were present."

\section{Hypo- and Hyperthermia}

Four studies have addressed the relation between hypoand hyperthermia and pbtO2 [97-99, 202]. One study of 72 severe TBI patients reports that: “...hyperthermia does not seem to reduce pbtO2 or increase the number of episodes of brain tissue hypoxia in patients with severe TBI. This provides evidence to support their conclusion: "These results suggest that hyperthermia may worsen outcome after TBI through mechanisms that may be separate from compromised brain oxygen" [99]. A study of 30 severe TBI patients reports that: “...brain tissue PO2 decreased with hypothermia, with a significant reduction below 35 degrees C [97]". The effects of mild hypothermia [34 -36 degrees C] was studies in 33 severe TBI patients who had persistent increased ICP $>20 \mathrm{mmHg}$. In keeping with the previous study they report that: "Mild induced hypothermia decreased brain oxygen significantly from $33 \pm 24 \mathrm{mmHg}$ to $30 \pm 22$ mmHg $(\mathrm{p}<0.05)$ " [98].

The effects of mild hypothermia on pbrO2 in a large series of 148 TBI patients are not uniform [202]. PbtO2 increased in patients with GCS 5 to 8 and decreased in patients with GCS 3 and 4.

It is possible that cerebral oxygenation may influence the effects of hypothermia, which has been reported in an animal study [143].

TBI and SAH Patients who developed shivering during induced normothermia were studied. The authors report that shivering was associated with an overall pbtO2 reduction from $34.1 \pm 7.3$ to $24.4 \pm 5.5 \mathrm{mmHg}(\mathrm{P}<0.001)$, and they report a significant correlation between the magnitude of shivering-associated pbtO2 decrease [delta pbtO2] and circulating water temperature $(\mathrm{R}=0.82, \mathrm{P}<0.001)$. They, however, conclude that: "The clinical significance of shivering-induced decrease in brain tissue oxygenation remains to be determined" [290].

\section{Anemia}

"Anemia is frequently encountered in critically ill patients and adversely affects cerebral oxygen delivery and
pbtO2" [58]. One group reports in a series of 80 TBI patients that: "a Hemoglobin level no greater than $9 \mathrm{~g} / \mathrm{dl}$ (anaemia) was associated with compromised pbtO2 (pbtO2 $<20$ $\mathrm{mmHg}$ )" [297]. They also report that: "Anemia with simultaneous compromised pbtO2, but not anemia alone, was a risk factor for unfavorable outcome, irrespective of injury severity" [297].

Anaemia which is treated prompts investigations on the effects of packed red blood cell transfusion (RBCT) on pbtO2. One group reports a graded response of local cerebral oxygenation in a combined group of TBI and SAH patients. In $74 \%$ of patients they observed a pbtO2 increase but did not provide a suitable explanation why it fell in $26 \%$ of patients. Cerebral perfusion pressure, $\mathrm{CPP}, \mathrm{SaO} 2$, and $\mathrm{FiO} 2$ were similar before and after RBCT [298]. Another group reports in a series of sixty TBI Patients that "All of the patients with basal $\mathrm{PtiO}(2)<15 \mathrm{mmHg}$ showed an increment in pbtO2 versus $74.5 \%$ of patients with basal pbtO2 or $=15 \mathrm{mmHg} \quad(p<0.01$, hour 3$)$." They conclude that Erythrocyte transfusion is associated with a variable and prolonged increment of cerebral tissue oxygenation in anemic patients with severe traumatic brain injury. Low baseline pbtO2 levels $(<15 \mathrm{mmHg})$ could define those patients who benefit the most from erythrocyte transfusion [3]. Another severe TBI series demonstrated that $57 \%$ of patients had a pbtO2 increase, whereas in $43 \%$ of patients, pbtO2 either did not change or decreased. pbtO2 improvement was not associated with baseline hemoglobin concentration or low pbtO2 $(<1 \mathrm{kPa})$ [299]. One paper reports that the effect of $\mathrm{RBCT}$ on pbtO2 is greater in women than in men [300].

The effects of RCBT in 17 children after severe TBI have also been reported [35]. The pbtO2 increase was transient and seen in $79 \%$ of RBCT. A transient decrease was seen in $21 \%$. The authors also report that: "Brain tissue oxygen tension returned to baseline within $24 \mathrm{hrs}$. Reliable predictors of this brain tissue oxygen tension response to blood transfusion, however, remain elusive." [35].

The aspect of storage duration of RPBC on the effects of pbtO2 has been studied in 66 anaemic male TBI patients [136]. The authors report that: "There was a significant short-lasting (3-4 hrs) increase in pbtO2 values after transfusion of erythrocytes stored for $<10$ days, 10-14 days, or 15-19 days, compared with those at baseline. In contrast, no significant changes in pbtO2 were observed after transfusion of erythrocytes stored $>19$ days" [136]. Similar findings have been confirmed elsewhere in an animal study [135].

\section{Clazosentan}

The effects of Clazosentan, a selective endothelin receptor subtype A antagonist, on pbtO2 in SAH patients in a phase IIa study have been reported with so far little effects [46]. A non-peer reviewed paper reports on the effects of intraoperative intracisternal subarachnoid sodium nitroprusside (SNP) administration in patients with aneurysmal SAH [204]. High-dose intra-arterial verapamil for the treatment of cerebral vasospasm after subarachnoid hemorrhage Verapamil caused no significant pbtO2 changes [301]. 


\section{Cerebral Angiography}

One study reports on the utility of pbtO2 monitoring during cerebral angiography [68]. In their series of 14 patients four patients showed a linear pbtO2 decrease which indicated cerebral hypoxia without ICP elevation when the cerebral catheter was advanced through cervical vessels. They also report significant correlations between severe intracranial angiographic arterial caliber reduction and reduced pbtO2 values, which was also reflected in an increased number of ischemic lesions on CT imaging [68].

\section{CPP Management}

Based on an analysis of 18 comatose intracerebral hemorrhage patients it has been suggested that: “...pbtO2 monitoring can be used to identify CPP targets for optimal brain tissue oxygenation" [76]. A paper with 30 poor grade SAH patients reports that metabolic crisis and BTH are associated with mortality and poor functional recovery after $\mathrm{SAH}$. CPP levels $<70 \mathrm{~mm} \mathrm{Hg}$ was associated with metabolic crisis and brain tissue hypoxia, and may increase the risk of secondary brain injury in poor-grade SAH patient [302]. The role of CPP management in severe TBI patients has been adressed in light of pbtO2 measurements in order to restore "normal" cerebral oxygenation, i.e. $\geq 25 \mathrm{mmHg}$. A combination of sedation and CPP augmentation were effective in 73 and $66 \%$ of episodes of compromised brain oxygen, respectively [303]. A report in poor grade $\mathrm{SAH}$ patients which adresses the relationship between CPP, ICP and pbtO2 confirms the observation that ICP and CPP monitoring "... may not always detect episodes of cerebral compromise in SAH patients" [304]. They suggest that: "...several complementary monitors may be needed to optimize the care of poor-grade SAH patients", i.e. cerebral microdialysis and pbtO2 [304]. Similar reports have been presented for TBI patients [305]. Another groups reports similar finding which represents an important clinical aspect: "CPP and ICP should not be used as surrogates for pbtO2 since cerebral oxygenation varies independently of cerebral hemodynamics and pressures" [306]. This finding is again supported by a series of 16 TBI patients in which the authors conclude that:" No clear relationship was found between the temporal pattern of cytokines and the behavior of the intracranial pressure, brain tissue oxygenation, and the presence or absence of swelling in the computed tomography scan" [196]. This finding has been confirmed in children: "Although very high ICP is associated with reduced pbtO2, in general, absolute ICP has a poor relationship with pbtO2" [307].

\section{Applied Physiology}

More complex physiological matters, which have attracted much attention in neurocritical care have also been addressed using pbtO2 technology: the role of cerebral autoregulation monitoring, i.e. the link between mechanisms of cerebral vascular regulation and cerebral oxygenation regulation [30, 141, 216, 242, 308, 309]. Studies have shown that the mechanisms are closely linked $[4,49,54,72,178$, $222,223,258,310,311]$. Of note, it has been reported that "The severity of brain tissue oxygenation derangement correlates with increasing cerebrovascular dysautoregulation in patients succumbing to severe head injury,..." [4]. One study has concluded that "Assessment of pbtO2- autoregulation gives valuable information on which patient will benefit from an increase in CPP and which CPP should be achieved to do so" [49]. This finding is in keeping with the suggestion that CPP elevation may be beneficial for ICP control and pbtO2 management in selected patients after TBI, those with intact cerebral autoregulation [199, 223].

Further support for this therapeutic concept is provided from a series of 38 TBI patients: "Driving cerebral perfusion pressure in excess of optimal cerebral perfusion pressure does not yield improvements in brain tissue oxygen after head injury and should be avoided, whereas cerebral perfusion pressure below optimal cerebral perfusion pressure may result in secondary cerebral ischemia" [258].

This view has recently been challenged with the authors' conclusions: "We show that pbtO2 generally tracks the direction of CPP irrespective of the state of cerebral autoregulation" [309]. It must be noted, however, that their study examines spontaneous CPP changes while others have investigated pharmacologically induced $\mathrm{CPP}$ variations [178].

$\mathrm{PbtO} 2$-based autoregulation monitoring using an index named "ORx" has also been investigated in SAH patients $[54,59,312,313]$. The authors report that "ORx values from days 5 and 6 after SAH carried predictive value for the occurrence of delayed infarction but before this event ultimately occurred" [54]. They conclude that "ORx indicates impaired autoregulation in patients who develop delayed infarction after SAH [54]. Furthermore, this index may distinguish between patients who finally develop delayed infarction and those who do not [54]." Such identification would allow timely interventions during the so called "window of opportunity" [54]. A larger series has raised the issue that: "The status of cerebrovascular autoregulation (measured by the ORx) might be an important pathophysiological factor in the disease process after SAH because impaired autoregulation was independently associated with an unfavorable outcome" [59].

The utility of the ORx for TBI patients, however, has been questioned [308]. A preliminary study in SAH patients could not confirm the utility of the ORx Index [41], however, methodological issues makes comparison of study results difficult [310]. An observational pilot study showed that ORx is severely disturbed in the edematous perihemorrhagic tissue after spontaneous intracerebral hemorrhage [69].

One animal study in which pbtO2 monitoring is compared with near infrared spectroscopy [NIRS] measurements $(\mathrm{rSO}[2])$ in pigs during cardiopulmonary resuscitation is noteworthy because transcutaneous NIRS monitoring is commonly used in cerebro- and cardiovascular surgery [123]. The authors report that in contrast to transcutaneous NIRS measurements, NIRS readings obtained from skull showed a significant correlation to brain tissue oxygen partial pressure values. This study questions the validity of commonly used transcutaneous NIRS measurements. Similar evidence is provided from a series of 22 TBI patients: "In patients with severe TBI, pbtO2 and $\mathrm{rSO}(2)$ were directly and significantly related. Severe intracerebral hypoxia was better detected by $\mathrm{rSO}(2)$ than was moderate intracerebral hypoxia. However, the diagnostic 
accuracy of $\mathrm{rSO}(2)$ was limited, and this measure should not be considered a substitute for routine pbtO2 monitoring." [243].

Another animal study is noteworthy [126]. The authors describe the effects of volatile anesthetics on pbtO2 and other physiological parameters at various $\mathrm{FiO} 2$ levels. They conclude that "cerebral PO2 cannot be inferred directly from measurements of other parameters, indicating that methodology incorporating continuous direct measurement of brain oxygen will lead to a better understanding of cerebral oxygenation under anesthesia and hypoxia."

One animal study has aimed to define the optimal chest compression/ventilation ratio for basic life support [BLS] using pbtO2 recordings. They conclude that: "During BLS, a compression/ventilation-ratio of 100:5 seems to be equivalent to $30: 2$, while ratios of 100:2 or compressionsonly deteriorate peripheral arterial oxygenation and reduce the chance for return of spontaneous circulation" [108].

\section{Cerebral Circulatory Arrest and Brain Death}

$\mathrm{PbtO} 2$ monitoring in 6 patients with cerebral circulatory arrest has been investigated. The authors point out that pbtO2 "...decreased toward $0 \mathrm{mmHg}$ as ICP increased and $\mathrm{CPP}$ decreased. $\mathrm{PbtO} 2$ reached 0 only when there was clinical evidence for brain death (BD). During the subsequent 12 hours until the second (BD) examination, pbtO2 remained $0 \mathrm{mmHg}$ and did not respond to oxygen challenge". They contrast these patients to five other patients in whom pbtO2 was $0 \mathrm{mmHg}$ but who were not brain-dead. They report that: "These episodes were transient $(<30$ minutes) and responded to an oxygen challenge, directed treatment or catheter replacement". They conclude that "A sustained ( $>30$ minutes) brain pbtO2 of 0 is consistent with $\mathrm{BD}$ " and they suggest that "...pbtO2 may be used to determine when a $\mathrm{BD}$ examination is appropriate in the pharmacologically suppressed patient" [88].

Further investigation into the reliability of clinical variables and neuromonitoring data as predictors of brain death shows that patients at risk of progressing to BD were those with low pbtO2 $(<16 \mathrm{mmHg})$ on admission and during the first 24 hours of neuromonitoring [314]. Multivariate logistic regression showed that a low pbtO2 level on admission was the best independent predictor for BD [314]. Similar evidence is provided in a study which reports that: "The first 72 hours of pbtO2 neurologic monitoring predicts mortality. When the pbtO2 monitor remains below $29 \mathrm{~mm}$ $\mathrm{Hg}$ in the first 72 hours of monitoring, mortality is increased" [255].

Brain tissue oxygenation in brain death has been published twice as in case series studies. The reports are quite uniform: "A sustained [ $>30$ minutes] brain pbtO2 of 0 is consistent with brain death [88] and " pbtO2 fell to 0 in all patients who experienced brain death, and all patients with pbtO2 of 0 experienced brain death. None of the 61 patients who did not experience brain death had confirmed pbtO2 readings of 0" [73]. The authors, however, do point out that larger series are needed to assess sensitivity and specificity. Similar experiences have been reported in a series of 5 children diagnosed with brain death [315].

\section{Safety Issues and Technical Considerations}

$\mathrm{PbtO} 2$ monitoring is considered safe in both children and adults $[13,23-25,30,316]$. There are no published reports that persons involved in direct care of the patients have been harmed or injured while using pbtO2 monitoring technology. Several papers have by now systematically addressed technical issues related to using pbtO2 monitoring technology [13, 71, 130, 177, 317-319].

One paper reports two "clinically relevant" cerebral hemorrhages in 23 catheter insertions. Few further details are presented except for the fact that one of the two patients had an AVM which was considered the source of bleeding while the other remained "unexplained". Obviously this latter case was not large enough to require surgical evacuation [91]. Although no other adverse effects using pbtO2 monitoring have been published 3 cases of acute subdural hematoma related to pbtO2 monitoring probe insertion are known to the first author! The outcomes of these cases are unknown. The second author has not encountered problems other than very few minor haemorrhages along the catheter trajectory in $>$ 150 probe insertions.

\section{Catheters - Pros and Cons}

If one assumes that the insertions techniques and all monitoring algorithms for all cathethers are very alike the question becomes which one to use for one's own unit and clinical practise? There are no relevant technical pros or cons for any catheter which a priori precludes using any of them. The differences of the measurement principles are stated above in the paper.

Based on the authors and their colleagues' experiences it is not only important to understand the basics and principles of each technology but also to become familiar with one's own technology and know its potential clinical shortcomings. This section is designed to show all comparative papers, both peer-reviewed and non-peerreviewed, in order to achieve this goal.

\section{LICOX}

Some authors consider the Licox probe the "gold standard" [71]. It does not represent the authors' opinion and it is likely that it is the "non-gold standard". It must be noted that the Licox technology uses a Clark-type electrode which is the most widely established partial pressure of oxygen monitoring device - it is used in the great majority of all original publications.

In 1998 a comprehensive study has addressed technical considerations and safety issues. 118 Licox catheters, which were used in 101 patients were assessed [13]. This paper includes finding of a previous publication based on an assessment of 73 catheters [317]. The results are as follows:

1. Small iatrogenic hematomas were observed for two patients $(1.7 \%)$. This number compares favorably to what has been published for similar monitoring devices, e.g. intraparenchymal intracranial pressure monitoring. This number is much smaller to what has been published for external ventricular drains which are widely for treatment of TBI patients. 
2. No infection occurred after $6.7 \pm 3.9$ days. This number compares to what has been published (see 1 . Above)

3. The technical complication (dislocation or defect) rate was $13.6 \%$. This figure is higher to what has been published (see 1. Above). It does, however, not translate into patients' harm because it relates to technical malfunction. Such technical complications incur increased expenses because a fresh sensor is required.

4. The mean adaptation time was $79.0 \pm 51.7 \mathrm{~min}$. This number relates to this particular monitoring technology.

5. The greatest PO2 display errors were measured during the first 4 days of continuous monitoring. There is no comparable data to further comment on this number.

6. The maximal probe display error was $1.07 \pm 2.14 \%$, tested at temperatures between 22 degrees $\mathrm{C}$ and 37 degrees $\mathrm{C}$ and tested at oxygen pressures of 0,44 , and $150 \mathrm{~mm} \mathrm{Hg}$. This number is low and is irrelevant for daily clinical practise.

7. The zero display error was $-0.21 \pm 0.25 \mathrm{~mm} \mathrm{Hg}$. This number is low and is irrelevant for daily clinical practise.

8. Excluding the first 1 hour after insertion, data are reliable, with almost $100 \%$ good data quality.

Similar features have been reported from other groups: No infections or hematomas, one catheter failure, and 2 transport-related dislodgements in $30 \mathrm{TBI}$ patients monitored with Licox [18]. This paper notes a six-hour hyperoxia treatment due to misinterpretation of treatment algorithms [18].

One paper reports that recordings in 5 out of 186 patient recordings obtained with Licox probes were excluded from an analysis because the drift exceeded preset limits without further details provided [276].

An extensive institutional practise review of 61 cases of multimodality monitoring, including 59 cases in which pbtO2 was monitored reports an unusually high percentage of device malfunction or dislodgement of $43 \% ; n=26$. Their hematoma- and infection rates were 3 and $5 \%$, respectively, which includes a wide range of invasive cerebral monitors. Wit regard to the Licox probe they report a $17 \%$ hardware malfunction rate and discuss the possible reasons for that high number. They did, however, not return the devices to the manufacturer for further assessment of "hardware malfunction". They also report one large right frontal hematoma upon monitor insertion in a patient who was taking two antiplatelet function medications They conclude that: "...collaboration among institutions is necessary to establish practice guidelines for the choice and placement of multimodal monitors. Further advancement in device technology is needed to improve insertion techniques, interdevice compatibility, and device durability, ..." [320]. Some authors advocate a post-probe-insertion CT to ensure correct placement [237, 267, 304].

\section{LICOX AND NEUROTREND}

In vitro accuracy, long-term drift and response-time were addressed in a paper published in 2005 [177]. This paper also compares the Neurotrend and Licox system. The authors conclude:

1. Both systems measure oxygen tension sufficiently.

2. Licox technology measures more accurately than Nerotrend.

3. Neurotrend sensors read significantly lower pO2 in $1 \% \mathrm{O}(2)$.

4. Neurotrend sensors show an increasing deviation with higher oxygen concentrations which was due to two of twelve probes.

5. A slight drift towards lower oxygen tension readings for both sensors, but more pronounced for the Neurotrend, does not impair long-term use.

A comparison is presented in a non-peer reviewed paper [130]. Using 49 Licox catheters in 42 patients the authors report that 37 patients [88\%] has artifact-free data collected. Using 50 Neurotrend catheters in 35 patients they had 14 patients $[40 \%]$ with artifact-free data collected. They report a $20 \%$ catheter/bolt breakage and $8 \%$ catheter/sensor malfunction for Neurotrend compared with $0 \%$ and $2 \%$ for Licox. In their series of 99 catheters total they report 2 hematomas, no further details on size or other details, however, are provided [130]. It is also noteworthy that monitoring-related infections did not occur.

Another non-peer reviewed Licox/ Para-Neurotrend in vitro comparative study [319] reports:

1. $95 \%$ response times were $102 \pm 13$ seconds for first generation Licox probes and $135 \pm 24 \mathrm{~s}$ for Paratrend.

2. Second generation probes were $134 \pm 4$ and $116 \pm 16$ $\mathrm{s}$ respectively.

3. At pO2 $150 \mathrm{mmHg}$ Licox and Paratrend probes were accurate with $2.2 \%$ and $2.1 \%$ error, respectively and $2.6 \%$ and $4.1 \%$ for later generation.

4. At pO2 $18 \mathrm{mmHg}$, Paratrend overestimated by $16.5 \%$ (absolute error range 2.18 to $4.18 \mathrm{mmHg}$ ), $7.4 \%$ for Neurotrend, Licox underestimated by $1.8 \%$ (absolute error range 0.08 to $0.52 \mathrm{mmHg}$ ) with $3.6 \%$ for the second generation probe.

The authors draw a sensible conclusion: "Although there were statistically significant differences between the first generation probe types, this difference may not be clinically relevant. Overestimation of $\mathrm{pO} 2$ by Neurotrend and small underestimation by Licox partially explain differences in published thresholds for cerebral ischemia. The Neurotrend was slightly more accurate and faster than the Paratrend system." [319].

Additional aspects of a direct Licox-Neurotrend comparison were reported in a non-peer reviewed study in 7 TBI/SAH patients [259]:

1. Mean PtiO2 was generally lower when assessed by the Neurotrend, as compared with the Licox [Licox $27.7 \mathrm{mmHg} v s$ Neurotrend $20.9 \mathrm{mmHg}$. 
2. The amplitude of PtiO2 elevations during ventilation with $100 \%$ oxygen was higher with the Licox, but this did not reach statistical significance (Licox 55.2 mmHg vs Neurotrend $50.2 \mathrm{mmHg}$ ).

3. Regarding clinical stability of the sensors, only one Neurotrend sensor provided valid function over the desired monitoring period. Five Neurotrend sensors dislocated or broke and one sensor did not show any function after insertion.

4. No malfunction occurred with the Licox sensors.

\section{LICOX PMO}

Formal testing results of the combined pbtO2temperature probe called "PMO" was published in 2008 [318]. Accuracy and response times of the PMO probe was assessed over a range of $\mathrm{PO} 2$ values and temperatures under controlled laboratory conditions. In addition they tested the automated card calibration system and describe their clinical experience. The authors report:

1. The new Licox PMO probe accurately measures oxygen tension over a wide range of oxygen concentrations and physiological temperatures, but it does have a small tendency to underestimate oxygen tension (mean error, $-3.8 \pm 3.5 \%$ ) that is more pronounced between the temperatures of 33 and 39 degrees $\mathrm{C}$.

2. The thermistor of the PMO probe also has a tendency to underestimate temperature when compared with a resistance thermometer (mean error: $-0.67 \pm 0.22 \mathrm{C}$ ).

3. The card calibration system was also found to introduce some variability in measurements of oxygen tension when compared with a manually calibrated system.

4. Clinical experience with the new probe indicates good placement within the white matter using the improved bolt system and low rates of hematoma $(2.9 \%)$, infection ( $0 \%)$, and dislodgement (5.9\%).

\section{LICOX AND NEUROVENT}

A formal comparison between Raumedic - Neurovent (NV) and Licox (LX) [215] yields the following:

1. In all gas concentrations, NV and LX sensors measured pO2 with high accuracy and stability in vitro (mean differences from calculated values were for $\mathrm{NV}$ 0.76-1.6 $\mathrm{mmHg}$ and for LX -0.46-0.26 $\mathrm{mmHg}$ ).

2. Both sensors showed a shorter response time to $\mathrm{pO} 2$ increase (for NV $56 \pm 22 \mathrm{~s}$ and for LX $78 \pm 21 \mathrm{~s}$ ) compared to pO2 decrease (for NV $131 \pm 42 \mathrm{~s}$ and for LX $215 \pm 63$ s).

3. NV pO2 values were more stable for changes in temperature, while LX sensors showed larger standard deviations with increasing temperature (the difference from the calculated values in $19.7 \mathrm{mmHg}$ $\mathrm{O}(2)$ at 40 degrees $\mathrm{C}$ were for $\mathrm{NV}$ probes between 0.5 and $1.7 \mathrm{mmHg}$ and $\mathrm{LX}$ between -2.3 and $1.9 \mathrm{mmHg}$ ).
4. Both sensors gave stable results with low standard deviations during long-term (10 days) use, but with a slight elevation of measured $\mathrm{pO} 2$ levels by time.

The conclusions are: "Both NV and LX were accurate in detecting different oxygen tensions, and they did not deviate over longer recording times. However, LX needed a significantly longer time to detect changes in pO2 levels compared to NV. Furthermore, LX probes showed an increased standard deviation with higher temperatures." Similar to the data presented above [319] these differences are unlikely to be clinically significant.

Another formal comparison between Raumedic Neurovent (NV]) and Licox (LX) is available [71]. This group reports:

1. The average of individual mean $\mathrm{pbtO} 2$ measurements showed no relevant differences between the Licox $(19.5 \pm 7.1)$ and Neurovent multiparameter probe (21.7 \pm 9.5$)$.

2. Twenty-eight Licox probes out of 30 showed proper functioning over the desired monitoring period. Raumedic multiparameter probes displayed a higher malfunction/handling error frequency (2 device errors, 11 handling errors).

3. A comparison of the pbtO2 data between the Licox and Raumedic systems according to Bland and Altman was possible in 18 out of 30 patients and showed acceptable results (mean difference $-1.24 \mathrm{~mm}$ $\mathrm{Hg}$; limits of agreement: -25.1 to $+22.6 \mathrm{~mm} \mathrm{Hg}$ ). A total of $95.2 \%$ of 96,083 recordings was within the calculated limits of agreement.

4. Ex vivo tests of the probes after explantation revealed stable ICP and TBr function of the Raumedic probe. Precision of Zero pbtO2 did not differ between the probes, whereas precision of the $150 \mathrm{~mm} \mathrm{Hg}$ pbtO2 was greater in the Raumedic probes.

Their conclusions are: "Interpretation of our data is limited by several factors: [1] monocentric study; [2] reduced mechanical probe stability, handling difficulties with the double lumen bolt; [3] design changes to improve mechanical stability will require further study; [4] conflict of interest with Raumedic because of its support for the study. The conclusion drawn from our study is that the new multiparameter probe evaluated does measure ICP, $\mathrm{TBr}$, and pbtO2. But all the initial data given in this paper have to be interpreted cautiously. A new study will be necessary when the mechanical stability of the new probe has been improved".

A peer reviewed, yet preliminary formal comparison in eleven SAH and TBI patients with simultaneously recorded Licox and Neurovent pbtO2 for ORx calculation reports a mean ORx difference of 0,1 with Licox producing higher values [313]. ORx agreement was between -0.6 to +0.7 . For the calculation of the optimal CPP (CPP[opt)), based on cerebral autoregulation assessment, they report a mean difference of $0 \mathrm{mmHg}$, however the limits of agreement ranged between -16.5 and $+16.4 \mathrm{mmHg}$. They conclude that: " The main result is that Licox and Raumedic showed consistent differences in ORx and CPP(opt). Therefore, ORx values of both probes cannot be interchanged and should not 
be viewed as equivalent. This should be taken into consideration when discussing ORx data generated by different pbtO2 probe types" [313].

Another formal comparison between the Neurovent PTO and the Licox probe was carried out in an animal model [321]. Probes were compared on seven manoeuvers (a) baseline measurements followed by (b) hyperoxygenation (fraction of inspired oxygen $($ Fio2 $)=1.0$ ), medically induced (c) hypo- and (d) hypertension, (e) hyperventilation, (f) trishydroxymethylaminomethane application, and hypoxygenation $($ Fio $2<0.05)$. The authors report that:

1. Both probes show good comparability under baseline conditions (meandiff $2.09 \mathrm{~mm} \mathrm{Hg}$, standard deviation $0.04 \mathrm{~mm} \mathrm{Hg}$, range 1.98-2.20 $\mathrm{mm} \mathrm{Hg}$ ).

2. Measurement dynamics during hyperoxygenation (Fio2=1.0) revealed significantly different profiles, eg Neurovent-TO probe reached up to 1.53 -fold higher pbtO2 values than the Licox probe.

3. During hypoxygenation (Fio $2<0.05$ ), the NeuroventTO probe detected the hypoxic level of $8.5 \mathrm{~mm} \mathrm{Hg}$ 1.5 minutes earlier than did the Licox probe.

4. All other maneuvers showed similar responses in both technologies. The authors conclude that: "The Neurovent-TO PbrO2 device comparably measures $\mathrm{PbrO} 2$ under most conditions tested compared with the Licox device. The Neurovent-TO is more sensitive to rapid Fio2 changes. Further studies are necessary to clarify these differences. It is questionable whether existing knowledge of Licox tissue oxygenation, ie, hypoxic threshold, can be directly transferred to the Neurovent-TO [321].

Four other, yet non peer reviewed, Licox-Neurovent comparisons are available [166, 322-324].

The first paper with a series of seven SAH patients reports clinically acceptable, i.e. stable monitoring parameters [322]. They report:

1. Mean pbtO2 from Licox and Neurovent PTO was $16.1 \mathrm{t} / \mathrm{-} 9.0 \mathrm{mmHg}$ and $17.5 \mathrm{t} / \mathrm{-} 11.9 \mathrm{mmHg}$ respectively.

2. Mean ORx was $0.35+/-0.44$ and $0.31+/-0.43$ respectively.

3. The pbtO2 difference was $-2.73+/-10.1 \mathrm{mmHg}$ (Licox - Raumedic).

4. The difference for the calculated ORx was far smaller (0.03 +/- 0.31; Licox - Raumedic) and the correlation coefficient higher than for both pbtO2 values $(0.76$ for ORx vs 0.56 for pbtO2) [322].

The second paper reports on the testing of eight Licox and eight Neurovent-PTO sensors for $10 \mathrm{~min}$ at $37{ }^{\circ} \mathrm{C}$, atmospheric pressure, at an oxygen content of $0 \%$ and $100 \%$ before and after the in vivo test. The same probes were implanted in pigs, which underwent hepatectomy. A $100 \%$ $\mathrm{FiO} 2$ challenge for $10 \mathrm{~min}$ was performed $2 \mathrm{~h}$ post-abdominal surgery [323].

They report:
1. At $0 \% \mathrm{O} 2$ content values varied from 0.2 to $7 \mathrm{mmHg}$, at $100 \% \mathrm{O} 2$ content from 130 to $165 \mathrm{mmHg}$. No difference between probes was found.

2. In vivo tests: Raumedic showed statistically significant higher pbtO2 (mean $+6.3 \mathrm{mmHg}$ ) compared with Licox.

3. During $\mathrm{O} 2$ challenge, both probes responded similarly; however, Raumedic had a 10\% higher, statistically significant response amplitude.

4. After explantation there was again no difference between the two sensors.

They conclude that Neurovent sensors measured higher pbtO2 values. There was no significant difference regarding overall measurement of in vitro accuracy between the two probes, which proved to be robust when used consecutively for longer periods and in different environments [323].

The third paper reports on $18 \mathrm{TBI}$ and SAH with simultaneous Licox and Neurovent pbtO2 measurements [324].

They report:

1. Both types of probes were able to display spontaneous pbtO2 fluctuations and reactions to therapy.

2. Mean measurement difference between the probes was $-2.3 \mathrm{mmHg}$, with corresponding $95 \%$ limits of agreement of -32.3 to $27.5 \mathrm{mmHg}$.

3. Regarding an ischemia threshold of $15 \mathrm{mmHg}$, both probes were in agreement in $78 \%$ and showed disparate results in $22 \%$.

They conclude that: "Our data suggest that the pbtO2 measurements of the two systems cannot be interchanged. Although we were unable to determine which system delivers more valid data, we do think that more rigorous testing is necessary before implementing the new probe in clinical routine" [324].

The fourth and final paper, which is an animal study with simultaneous Licox and Neurovent recordings after hepatectomy in swine reports that:

1. Despite a statistically significant mean pbtO2 difference of $6.2 \mathrm{mmHg}$, the mean ORx (Licox) was 0.139 , the mean ORx(Neurovent) was 0.146 ( $\mathrm{p}=$ 0.2098).

2. Correlation coefficient of ORx values assessed every minute and every hour was 0.52 and 0.58 respectively.

3. They conclude that: "Despite this significant difference in absolute pbtO2 values the derived mean ORx values were not different. Similar to the established Licox system, the Raumedic system seems to enable a valid ORx recording [166].

\section{LICOX AND FOXY AL-300}

Performance of the Licox and the Foxy AL-300 system was compared in an animal study [247]. They took measurements at (a) baseline with 100\% FiO2, (b) during episodes of apnea, and (c) during recovery at 100\% FiO2. 
They report

for (a): Foxy-ptiO(2) 62+/-24 mm Hg, and Licox-ptiO(2) $55+/-29 \mathrm{~mm} \mathrm{Hg}$,

for (b): Foxy-ptiO(2) 37+/-12 mm Hg, and Licox-ptiO(2) $31+/-16 \mathrm{~mm} \mathrm{Hg}$,

for (c): Foxy-ptiO(2) 78+/-26 mm Hg, and Licox-ptiO(2) $62+/-32 \mathrm{~mm} \mathrm{Hg}$,

with no further statistical analysis. The authors conclude that: "The present study demonstrates the feasibility of pO2 measurements in ... cerebral microcirculation using a novel uncoated fluorescence quenching probe. The technology (Foxy AL-300) allows for real-time investigation of $\mathrm{pO} 2$ changes at a temporal resolution of 0.05 to $10 \mathrm{~Hz}$ " [247].

\section{PbtO2 Monitoring Reviews \& Critical Appraisal}

After pbtO2 monitoring technology has been introduced into clinical practise in the mid 1990's it has been subjected to several formal reviews with an increasing number since $2003[1,130,171-173,175,185,186,188,190,192,195$, $198,200,206,208-210,214,231,233,273,325-346]$. This increasing number reflects the fact that pbtO2 monitoring has established itself as an additional monitoring tool for neurointensive care [347]. It has even been said to be "... as close to a gold standard of cerebral oxygenation as we have at the bedside" [233]. The Licox Clark type electrode is considered a reference or "gold standard" electrode in experimental setups [247, 261]. All but one review indicate that this technology is useful for routine clinical practise [206]. This paper recommends that both AVDO2 monitoring and pbtO2 monitoring should only be used for scientific research based on the conclusion that these technologies have at present not been demonstrated to be associated with a clinical benefit [206]. A similar yet less conclusive statement is presented in another review [188]. The authors point out that "...pbtO2 monitoring may allow one to find individual trends and to react therapeutically to counter local tissue ischemia but must not be mistaken for a 'crystal ball' that can predict the ultimate outcome" [188]. It has also been emphasized that the surgeon/physician in charge of pbtO2 monitoring must have experience in data interpretation: "It is equally important that the clinician understands relevant aspects of brain oxygen physiology and head trauma pathophysiology to enable correct interpretation of the monitored data and therefore to direct an appropriate therapeutic response that is likely to benefit, not harm, the patient" [348].

Three reviews have underlined the known fact of a lack of a randomized trial to prove the utility of pbtO2 monitoring which, speaking from a strictly scientific point of view, is needed to recommend its unrestricted routine use [200, 273, 325]. In keeping with this view a recent comprehensive pbtO2 review concludes that the current scientific literature implies that: "... These results imply that treating patients to increase pbtO2 may improve outcome after severe TBI. This question will require further study" [316]. This group has previously suggested that:...pbtO2 monitoring might even have the potential to improve outcome [226].

If clinicians, however, were to restrict all monitoring modalities unless proven by such trials were available, little if any routine neuromonitoring would be established.
A 2010 paper including 41 severe TBI reports that: "The use of pbtO2 monitors to guide therapy was associated with higher cumulative fluid balance, more vasopressor use, and the development of both pulmonary edema and refractory intracranial hypertension" [20]. They also report that patients who had a pbtO2 monitor had a worse neurological outcome. Although the authors present various approaches to account for this association a conclusive explanation is not presented.

\section{CONCLUSIONS}

Based on this review it is concluded that pbtO2 monitoring technology is a safe and valuable cerebral monitoring device in neurocritical care. Its clinical utility has repeatedly been clearly confirmed because it adds a monitoring parameter, independent to established cerebral monitoring devices. Pathologic values have been established in peer-reviewed research, which are not only relevant to outcome but are treatable.

The effects of virtually all ICU treatment modalities on cerebral oxygenation have been investigated, and pbtO2 monitoring technology offers new insights into cerebral physiology and pathophysiology. The benefits clearly outweigh the risks, which remains unchallenged in almost all publications retrieved except for two. It is particular attractive because it offers continuous, real-time data and it is available at the bedside.

This technology represents an invasive cerebral monitoring modality which requires cranial access and harbors a small risk of causing subdural or intraparenchymal hematoma. It should only be used in units which have experience with comparable monitoring devices, e.g. intracranial pressure monitoring. It appears helpful to establish guidelines for safe practise [218, 332, 349].

Only a randomized trail, which is currently under way, will eventually prove that pbtO2 monitoring will lead to improved outcome in any of the conditions for which this technology is currently used.

\section{CONFLICT OF INTEREST}

The authors confirm that this article content has no conflict of interest.

\section{ACKNOWLEDGEMENTS}

Declared none.

\section{DISCLOSURES}

Erhard Lang is a member of the Integra Speakers Bureau and consults Integra for complaints received with the use of Licox probes. Matthias Jaeger has nothing to disclose.

\section{REFERENCES}

[1] Lang EW, Mulvey JM, Mudaliar Y, Dorsch NW. Direct cerebral oxygenation monitoring--a systematic review of recent publications. Neurosurg Rev 2007; 30(2): 99-106; discussion -7.

[2] Thorat JD, Wang EC, Lee KK, Seow WT, Ng I. Barbiturate therapy for patients with refractory intracranial hypertension following severe traumatic brain injury: Its effects on tissue oxygenation, brain temperature and autoregulation. J Clin Neurosci 2008; 15(2): 143-8.

[3] Leal-Noval SR, Rincon-Ferrari MD, Marin-Niebla A, et al. Transfusion of erythrocyte concentrates produces a variable increment on cerebral oxygenation in patients with severe traumatic 
brain injury: a preliminary study. Intensive Care Med 2006; 32(11): 1733-40.

[4] Ang BT, Wong J, Lee KK, Wang E, Ng I. Temporal changes in cerebral tissue oxygenation with cerebrovascular pressure reactivity in severe traumatic brain injury. J Neurol Neurosurg Psychiatry 2007; 78(3): 298-302.

[5] Sarrafzadeh AS, Sakowitz OW, Callsen TA, Lanksch WR, Unterberg AW. Detection of secondary insults by brain tissue pO2 and bedside microdialysis in severe head injury. Acta Neurochir Suppl 2002; 81: 319-21.

[6] Stiefel MF, Heuer GG, Smith MJ, et al. Cerebral oxygenation following decompressive hemicraniectomy for the treatment of refractory intracranial hypertension. J Neurosurg 2004; 101(2): 241-7.

[7] Strege RJ, Lang EW, Stark AM, et al. Cerebral edema leading to decompressive craniectomy: an assessment of the preceding clinical and neuromonitoring trends. Neurol Res 2003; 25(5): 5105.

[8] van Santbrink H, Schouten JW, Steyerberg EW, Avezaat CJ, Maas AI. Serial transcranial Doppler measurements in traumatic brain injury with special focus on the early posttraumatic period. Acta Neurochir (Wien) 2002; 144(11): 1141-9.

[9] Jia J, Lin YQ, Liu WF, et al. Study of the effects of mild hypothermia on cerebral $\mathrm{PO} 2, \mathrm{PCO} 2$ and $\mathrm{pH}$ and body temperature in patients with acute severe head injury. Chin J Traumatol 2005; 8(3): 138-41.

[10] $\mathrm{Ng}$ I, Lim J, Wong HB. Effects of head posture on cerebral hemodynamics: its influences on intracranial pressure, cerebral perfusion pressure, and cerebral oxygenation. Neurosurgery 2004; 54(3): 593-7; discussion 8.

[11] Reinert M, Barth A, Rothen HU, Schaller B, Takala J, Seiler RW. Effects of cerebral perfusion pressure and increased fraction of inspired oxygen on brain tissue oxygen, lactate and glucose in patients with severe head injury. Acta Neurochir (Wien) 2003; 145(5): 341-9; discussion 9-50.

[12] Dings J, Jager A, Meixensberger J, Roosen K. Brain tissue pO2 and outcome after severe head injury. Neurol Res 1998; 20 Suppl 1: S71-5.

[13] Dings J, Meixensberger J, Jager A, Roosen K. Clinical experience with 118 brain tissue oxygen partial pressure catheter probes. Neurosurgery 1998; 43(5): 1082-95.

[14] Meixensberger J, Jager A, Dings J, Baunach S, Roosen K. Multimodal hemodynamic neuromonitoring--quality and consequences for therapy of severely head injured patients. Acta Neurochir Suppl 1998; 71: 260-2.

[15] Brawanski A, Faltermeier R, Rothoerl RD, Woertgen C. Comparison of near-infrared spectroscopy and tissue $\mathrm{p}(\mathrm{O} 2)$ time series in patients after severe head injury and aneurysmal subarachnoid hemorrhage. J Cereb Blood Flow Metab 2002; 22(5): 605-11.

[16] Gasco J, Sendra J, Lim J, Ng I. Linear correlation between stable intracranial pressure decrease and regional cerebral oxygenation improvement following mannitol administration in severe acute head injury patients. Acta Neurochir Suppl 2005; 95: 73-7.

[17] Sakowitz OW, Stover JF, Sarrafzadeh AS, Unterberg AW, Kiening KL. Effects of mannitol bolus administration on intracranial pressure, cerebral extracellular metabolites, and tissue oxygenation in severely head-injured patients. J Trauma 2007; 62(2): 292-8.

[18] Adamides AA, Cooper DJ, Rosenfeldt FL, et al. Focal cerebral oxygenation and neurological outcome with or without brain tissue oxygen-guided therapy in patients with traumatic brain injury. Acta Neurochir (Wien) 2009; 151(11): 1399-409.

[19] Chang JJ, Youn TS, Benson D, et al. Physiologic and functional outcome correlates of brain tissue hypoxia in traumatic brain injury. Crit Care Med 2009; 37(1): 283-90.

[20] Fletcher JJ, Bergman K, Blostein PA, Kramer AH. Fluid balance, complications, and brain tissue oxygen tension monitoring following severe traumatic brain injury. Neurocrit Care 2010; 13(1): 47-56.

[21] Oddo M, Nduom E, Frangos S, et al. Acute lung injury is an independent risk factor for brain hypoxia after severe traumatic brain injury. Neurosurgery 2010; 67(2): 338-44.

[22] Meixensberger J, Jaeger M, Vath A, Dings J, Kunze E, Roosen K. Brain tissue oxygen guided treatment supplementing ICP/CPP therapy after traumatic brain injury. J Neurol Neurosurg Psychiatry 2003; 74(6): 760-4.
[23] Gracias VH, Guillamondegui OD, Stiefel MF, et al. Cerebral cortical oxygenation: a pilot study. J Trauma 2004; 56(3): 469-72; discussion 72-4.

[24] Narotam PK, Burjonrappa SC, Raynor SC, Rao M, Taylon C. Cerebral oxygenation in major pediatric trauma: its relevance to trauma severity and outcome. J Pediatr Surg 2006; 41(3): 505-13.

[25] Stiefel MF, Udoetuk JD, Storm PB, et al. Brain tissue oxygen monitoring in pediatric patients with severe traumatic brain injury. J Neurosurg 2006; 105(4 Suppl): 281-6.

[26] Figaji AA, Fieggen AG, Sandler SJ, Argent AC, Le Roux PD, Peter JC. Intracranial pressure and cerebral oxygenation changes after decompressive craniectomy in a child with traumatic brain swelling. Childs Nerv Syst 2007; 23(11): 1331-5.

[27] Ushewokunze S, Sgouros S. Brain tissue oxygenation changes in children during the first $24 \mathrm{~h}$ following head injury. Childs Nerv Syst 2009; 25(3): 341-5.

[28] Figaji AA, Fieggen AG, Argent AC, Leroux PD, Peter JC. Does adherence to treatment targets in children with severe traumatic brain injury avoid brain hypoxia? A brain tissue oxygenation study. Neurosurgery 2008; 63(1): 83-91; discussion -2 .

[29] Cavazzoni E, Schibler A. Monitoring of brain tissue oxygen tension and use of vasopressin after cardiac arrest in a child with catecholamine-induced cardiac arrhythmia. Crit Care Resusc 2008; 10(4): 316-9.

[30] Figaji AA, Zwane E, Fieggen AG, et al. Pressure autoregulation, intracranial pressure, and brain tissue oxygenation in children with severe traumatic brain injury. J Neurosurg Pediatr 2009; 4(5): 4208.

[31] Figaji AA, Sandler SI, Fieggen AG, Le Roux PD, Peter JC, Argent AC. Continuous monitoring and intervention for cerebral ischemia in tuberculous meningitis. Pediatr Crit Care Med 2008; 9(4): e2530 .

[32] Figaji AA, Zwane E, Thompson C, et al. Brain tissue oxygen tension monitoring in pediatric severe traumatic brain injury. Part 2: Relationship with clinical, physiological, and treatment factors. Childs Nerv Syst 2009; 25(10): 1335-43.

[33] Figaji AA, Zwane E, Thompson C, et al. Brain tissue oxygen tension monitoring in pediatric severe traumatic brain injury. Part 1: Relationship with outcome. Childs Nerv Syst 2009; 25(10): 1325-33.

[34] Figaji AA, Zwane E, Graham FA, Argent AC, Le Roux PD, Peter JC. The effect of increased inspired fraction of oxygen on brain tissue oxygen tension in children with severe traumatic brain injury. Neurocrit Care 2010; 12(3): 430-7.

[35] Figaji AA, Zwane E, Kogels M, et al. The effect of blood transfusion on brain oxygenation in children with severe traumatic brain injury. Pediatr Crit Care Med 2010; 11(3): 325-31.

[36] Allen BB, Hoffman CE, Traube CS, Weinstein SL, Greenfield JP. Continuous brain tissue oxygenation monitoring in the management of pediatric stroke. Neurocrit Care 2011; 15(3): 52936.

[37] Padayachy LC, Rohlwink U, Zwane E, Fieggen G, Peter JC, Figaji AA. The frequency of cerebral ischemia/hypoxia in pediatric severe traumatic brain injury. Childs Nerv Syst 2012; 28(11): 19118 .

[38] Schibler A, Humphreys S. Increased brain tissue oxygen tension in children with traumatic brain injury using temperature-corrected guided ventilation during prophylactic hypothermia. Crit Care Resusc 2012; 14(1): 20-4.

[39] Stippler M, Ortiz V, Adelson PD, et al. Brain tissue oxygen monitoring after severe traumatic brain injury in children relationship to outcome and association with other clinical parameters. J Neurosurg Pediatr 2012; 10(5): 383-91.

[40] O'Brien NF, Mella C. Brain tissue oxygenation-guided management of diabetic ketoacidosis induced cerebral edema* Pediatr Crit Care Med 2012; 13(6): e383-8.

[41] Barth M, Woitzik J, Weiss C, et al. Correlation of clinical outcome with pressure-, oxygen-, and flow-related indices of cerebrovascular reactivity in patients following aneurysmal SAH. Neurocrit Care 2010; 12(2): 234-43.

[42] Stuart RM, Claassen J, Schmidt M, et al. Multimodality neuromonitoring and decompressive hemicraniectomy after subarachnoid hemorrhage. Neurocrit Care 2011; 15(1): 146-50.

[43] Bordes J, Boret H, Prunet B, Montcriol A, Goutorbe P. (Carotid dissection during angioplasty for vasospasm induced by subarachnoid haemorrhage. The use of multimodal cerebral 
monitoring). Ann Fr Anesth Reanim 2009; 28(12): 1023-8. [Dissection carotidienne au cours d'une angioplastie pour vasospasme apres hemorragie sous-arachnoidienne. Apport du monitorage cerebral "multimodal"].

[44] Al-Rawi PG, Tseng MY, Richards HK, et al. Hypertonic saline in patients with poor-grade subarachnoid hemorrhage improves cerebral blood flow, brain tissue oxygen, and pH. Stroke 2010; 41(1): 122-8.

[45] Arikan F, Vilalta J, Minoves T, et al. (Detection of episodes of ischemic tissue hypoxia by means of the combined intraoperative neurophysiologic monitoring with the tissue oxygenation monitoring in aneurysm surgery). Neurocirugia (Astur). 2008; 19(2): 113-20. [Deteccion de episodios de hipoxia tisular isquemica mediante la monitorizacionneurofisiologica intraoperatoria combinada con la monitorizacion de la oxigenaciontisular en la cirugia aneurismatica].

[46] Barth M, Capelle HH, Munch E, et al. Effects of the selective endothelin A (ET(A)) receptor antagonist Clazosentan on cerebral perfusion and cerebral oxygenation following severe subarachnoid hemorrhage - preliminary results from a randomized clinical series. Acta Neurochir (Wien) 2007; 149(9): 911-8; discussion 8.

[47] Jaeger M, Soehle M, Schuhmann MU, Winkler D, Meixensberger J. Correlation of continuously monitored regional cerebral blood flow and brain tissue oxygen. Acta Neurochir (Wien) 2005; 147(1): 51-6; discussion 6.

[48] Sarrafzadeh AS, Unterberg AW, Lanksch WR. Bedsidemicrodialysis for early detection of vasospasm after subarachnoid hemorrhage. Case report and review of the literature. Zentralbl Neurochir 1998; 59(4): 269-73.

[49] Soehle M, Jaeger M, Meixensberger J. Online assessment of brain tissue oxygen autoregulation in traumatic brain injury and subarachnoid hemorrhage. Neurol Res 2003; 25(4): 411-7.

[50] Jaeger M, Soehle M, Meixensberger J. Effects of decompressive craniectomy on brain tissue oxygen in patients with intracranial hypertension. J Neurol Neurosurg Psychiatry 2003; 74(4): 513-5.

[51] Stiefel MF, Heuer GG, Abrahams JM, et al. The effect of nimodipine on cerebral oxygenation in patients with poor-grade subarachnoid hemorrhage. J Neurosurg 2004; 101(4): 594-9.

[52] Gelabert-Gonzalez M, Fernandez-Villa JM, Ginesta-Galan V. Intra-operative monitoring of brain tissue $\mathrm{O} 2$ (PtiO2) during aneurysm surgery. Acta Neurochir (Wien). 2002; 144(9): 863-6; discussion 6-7.

[53] Reinprecht A, Greher M, Wolfsberger S, Dietrich W, Illievich UM, Gruber A. Prone position in subarachnoid hemorrhage patients with acute respiratory distress syndrome: effects on cerebral tissue oxygenation and intracranial pressure. Crit Care Med 2003; 31(6): 1831-8.

[54] Jaeger M, Schuhmann MU, Soehle M, Nagel C, Meixensberger J. Continuous monitoring of cerebrovascular autoregulation after subarachnoid hemorrhage by brain tissue oxygen pressure reactivity and its relation to delayed cerebral infarction. Stroke 2007; 38(3): 981-6.

[55] Muench E, Horn P, Bauhuf C, et al. Effects of hypervolemia and hypertension on regional cerebral blood flow, intracranial pressure, and brain tissue oxygenation after subarachnoid hemorrhage. Crit Care Med 2007; 35(8): 1844-51; quiz 52.

[56] Ramakrishna R, Stiefel M, Udoteuk J, et al. Brain oxygen tension and outcome in patients with aneurysmal subarachnoid hemorrhage. J Neurosurg 2008; 109(6): 1075-82.

[57] Shahlaie K, Boggan JE, Latchaw RE, Muizelaar JP. Posttraumatic vasospasm detected by continuous brain tissue oxygen monitoring: treatment with intraarterial verapamil and balloon angioplasty. Neurocrit Care 2009; 10(1): 61-9.

[58] Kurtz P, Schmidt JM, Claassen J, et al. Anemia is associated with metabolic distress and brain tissue hypoxia after subarachnoid hemorrhage. Neurocrit Care 2010; 13(1): 10-6.

[59] Jaeger M, Soehle M, Schuhmann MU, Meixensberger J. Clinical significance of impaired cerebrovascular autoregulation after severe aneurysmal subarachnoid hemorrhage. Stroke 2012; 43(8): 2097-101.

[60] Drummond JC, Sturaitis MK. Brain tissue oxygenation during dexmedetomidine administration in surgical patients with neurovascular injuries. J Neurosurg Anesthesiol 2010; 22(4): 33641.
[61] Jodicke A, Hubner F, Boker DK. Monitoring of brain tissue oxygenation during aneurysm surgery: prediction of procedurerelated ischemic events. J Neurosurg 2003; 98(3): 515-23.

[62] Cerejo A, Silva PA, Dias C, Vaz R. Monitoring of brain oxygenation in surgery of ruptured middle cerebral artery aneurysms. Surg Neurol Int 2011; 2: 70.

[63] Cerejo A, Silva PA, Dias C, Vaz R. Monitoring of brain tissue oxygenation in surgery of middle cerebral artery incidental aneurysms. Surg Neurol Int 2011; 2: 37.

[64] Silva PA, Cerejo A, Vilarinho A, Dias C, Vaz R. Regional variations in brain oxygenation during temporary clipping in aneurysm surgery. Neurol Res 2012; 34(10): 971-6.

[65] Ibanez J, Vilalta A, Mena MP, et al. Intraoperative detection of ischemic brain hypoxia using oxygen tissue pressure microprobes. Neurocirugia (Astur) 2003; 14(6): 483-9; discussion 90. [Deteccion intraoperatoria de hipoxia cerebral isquemica mediante sensores de presion tisular de oxigeno].

[66] Hoffman WE, Charbel FT, Edelman G, Ausman JI. Brain tissue gases and $\mathrm{pH}$ during arteriovenous malformation resection. Neurosurgery 1997; 40(2): 294-300; discussion -1.

[67] Pennings FA, Schuurman PR, van den Munckhof P, Bouma GJ. Brain tissue oxygen pressure monitoring in awake patients during functional neurosurgery: the assessment of normal values. J Neurotrauma 2008; 25(10): 1173-7.

[68] Carvi Y, Nievas M, Toktamis S, Hollerhage HG, Haas E. Hyperacute measurement of brain-tissue oxygen, carbon dioxide, $\mathrm{pH}$, and intracranial pressure before, during, and after cerebral angiography in patients with aneurysmatic subarachnoid hemorrhage in poor condition. Surg Neurol 2005; 64(4): 362-7; discussion 7.

[69] Diedler J, Karpel-Massler G, Sykora M, et al. Autoregulation and brain metabolism in the perihematomal region of spontaneous intracerebral hemorrhage: an observational pilot study. J Neurol Sci 2010; 295(1-2): 16-22.

[70] Carrera E, Schmidt JM, Fernandez L, et al. Spontaneous hyperventilation and brain tissue hypoxia in patients with severe brain injury. J Neurol Neurosurg Psychiatry 2010; 81(7): 793-7.

[71] Huschak G, Hoell T, Hohaus C, Kern C, Minkus Y, Meisel HJ. Clinical evaluation of a new multiparameter neuromonitoring device: measurement of brain tissue oxygen, brain temperature, and intracranial pressure. J Neurosurg Anesthesiol 2009; 21(2): 155-60.

[72] Imberti R, Fuardo M, Bellinzona G, Pagani M, Langer M. The use of indomethacin in the treatment of plateau waves: effects on cerebral perfusion and oxygenation. J Neurosurg 2005; 102(3): 455-9.

[73] Palmer S, Bader MK. Brain tissue oxygenation in brain death. Neurocrit Care 2005; 2(1): 17-22.

[74] Ho CL, Ang CB, Lee KK, Ng IH. Effects of glycaemic control on cerebral neurochemistry in primary intracerebral haemorrhage. $\mathrm{J}$ Clin Neurosci 2008; 15(4): 428-33.

[75] Wang E, Ho CL, Lee KK, Ng I, Ang BT. Changes in brain biochemistry and oxygenation in the zone surrounding primary intracerebral hemorrhage. Acta Neurochir Suppl 2008; 102: 293-7.

[76] Ko SB, Choi HA, Parikh G, et al. Multimodality monitoring for cerebral perfusion pressure optimization in comatose patients with intracerebral hemorrhage. Stroke 2011; 42(11): 3087-92.

[77] Francony G, Fauvage B, Falcon D, et al. Equimolar doses of mannitol and hypertonic saline in the treatment of increased intracranial pressure. Crit Care Med 2008; 36(3): 795-800.

[78] Helbok R, Kurtz P, Schmidt JM, et al. Effect of mannitol on brain metabolism and tissue oxygenation in severe haemorrhagic stroke. J Neurol Neurosurg Psychiatry 2011; 82(4): 378-83.

[79] Helbok R, Madineni RC, Schmidt MJ, et al. Intracerebral monitoring of silent infarcts after subarachnoid hemorrhage. Neurocrit Care 2011; 14(2): 162-7.

[80] Imberti R, Bellinzona G, Riccardi F, Pagani M, Langer M. Cerebral perfusion pressure and cerebral tissue oxygen tension in a patient during cardiopulmonary resuscitation. Intensive Care Med 2003; 29(6): 1016-9.

[81] Armonda RA, Vo AH, Bell R, Neal C, Campbell WW. Multimodal monitoring during emergency hemicraniectomy for vein of Labbe thrombosis. Neurocrit Care 2006; 4(3): 241-4.

[82] Stiefel MF, Zaghloul KA, Bloom S, Gracias VH, LeRoux PD. Improved cerebral oxygenation after high-dose inhaled aerosolized prostacyclin therapy for acute lung injury: a case report. J Trauma 2007; 63(5): 1155-8. 
[83] Bordes J, Boret H, Lacroix G, Prunet B, Meaudre E, Kaiser E. Decompressive craniectomy guided by cerebral microdialysis and brain tissue oxygenation in a patient with meningitis. Acta Anaesthesiol Scand 2011; 55(1): 130-3.

[84] Henry B, Emilie C, Bertrand P, Erwan D. Cerebral microdialysis and $\mathrm{PtiO} 2$ to decide unilateral decompressive craniectomy after brain gunshot. J Emerg Trauma Shock 2012; 5(1): 103-5.

[85] Helbok R, Beer R, Chemelli A, et al. Multimodal neuromonitoring in a patient with aneurysmal subarachnoid hemorrhage associated with aortic coarctation. Neurocrit Care 2011; 14(3): 433-7.

[86] Fahim DK, Luo L, Patel AJ, Robertson CS, Gopinath SP. Pulmonary embolus from acute superior sagittal sinus thrombosis secondary to skull fracture: case report. Neurosurgery $2011 ; 68(6)$ : E1756-60; discussion E60.

[87] Pennings FA, Bouma GJ, Kedaria M, Jansen GF, Bosch DA. Intraoperative monitoring of brain tissue oxygen and carbon dioxide pressures reveals low oxygenation in peritumoral brain edema. J Neurosurg Anesthesiol 2003; 15(1): 1-5.

[88] Smith ML, Counelis GJ, Maloney-Wilensky E, Stiefel MF, Donley $\mathrm{K}$, LeRoux PD. Brain tissue oxygen tension in clinical brain death: a case series. Neurol Res 2007; 29(7): 755-9.

[89] Whittle IR, Stavrinos N, Akil H, Yau Y, Lewis SC. Assessment of physiological parameters within glioblastomas in awake patients: a prospective clinical study. Br J Neurosurg 2010; 24(4): 447-53.

[90] Agren-Wilsson A, Eklund A, Koskinen LO, Bergenheim AT, Malm J. Brain energy metabolism and intracranial pressure in idiopathic adult hydrocephalus syndrome. J Neurol Neurosurg Psychiatry 2005; 76(8): 1088-93.

[91] Wessling H, Simosono CL, Escosa-Bage M, de Las HerasEcheverria P. Continuous cerebral $\mathrm{PtO}(2)$ measurements in awake patients as a diagnostic tool in suspected chronic adult hydrocephalus - a retrospective study of 10 cases. Acta Neurochir (Wien) 2007; 149(3): 239-44.

[92] Schmitt M, Eymann R, Antes S, Kiefer M. Intraventricular cooling during CSF infusion studies. Acta Neurochir Suppl 2012; 114: 2314.

[93] Bollo RJ, Williams SC, Peskin CS, Samadani U. When the air hits your brain: cerebral autoregulation of brain oxygenation during aerobic exercise allows transient hyperoxygenation: case report. Neurosurgery 2010; 67(2): E507-9.

[94] Park S, Roederer A, Mani R, et al. Limitations of threshold-based brain oxygen monitoring for seizure detection. Neurocrit Care 2011; 15(3): 469-76.

[95] Hoffman WE, Charbel FT, Edelman G. Desflurane increases brain tissue oxygenation and pH. Acta Anaesthesiol Scand 1997; 41(9): 1162-6.

[96] Johnston AJ, Steiner LA, Chatfield DA, et al. Effects of propofol on cerebral oxygenation and metabolism after head injury. $\mathrm{Br} \mathbf{J}$ Anaesth 2003; 91(6): 781-6.

[97] Gupta AK, Al-Rawi PG, Hutchinson PJ, Kirkpatrick PJ. Effect of hypothermia on brain tissue oxygenation in patients with severe head injury. Br J Anaesth 2002; 88(2): 188-92.

[98] Soukup J, Zauner A, Doppenberg EM, et al. Relationship between brain temperature, brain chemistry and oxygen delivery after severe human head injury: the effect of mild hypothermia. Neurol Res 2002; 24(2): 161-8.

[99] Spiotta AM, Stiefel MF, Heuer GG, et al. Brain hyperthermia after traumatic brain injury does not reduce brain oxygen. Neurosurgery 2008; 62(4): 864-72; discussion 72.

[100] Moppett IK, Hardman JG. Modeling the causes of variation in brain tissue oxygenation. Anesth Analg 2007; 105(4): 1104-12, table of contents.

[101] Moppett IK, Hardman JG. Development and validation of an integrated computational model of cerebral blood flow and oxygenation. Anesth Analg 2007; 105(4): 1094-103, table of contents.

[102] Nwaigwe CI, Roche MA, Grinberg O, Dunn JF. Effect of hyperventilation on brain tissue oxygenation and cerebrovenous PO2 in rats. Brain Res 2000; 868(1): 150-6.

[103] Sheehan J, Sherman J, Cifarelli C, et al. Effect of trans sodium crocetinate on brain tumor oxygenation. Laboratory investigation. J Neurosurg 2009; 111(2): 226-9.

[104] Ragoonanan TE, Beattie WS, Mazer CD, et al. Metoprolol reduces cerebral tissue oxygen tension after acute hemodilution in rats. Anesthesiology 2009; 111(5): 988-1000.
[105] Ma Y, Wu S. Simultaneous measurement of brain tissue oxygen partial pressure, temperature, and global oxygen consumption during hibernation, arousal, and euthermy in non-sedated and nonanesthetized Arctic ground squirrels. J Neurosci Methods 2008; 174(2): 237-44.

[106] Linner R, Werner O, Perez-de-Sa V, Cunha-Goncalves D. Circulatory recovery is as fast with air ventilation as with $100 \%$ oxygen after asphyxia-induced cardiac arrest in piglets. Pediatr Res 2009; 66(4): 391-4.

[107] Lee SJ, Hatran DP, Tomimatsu T, Pena JP, McAuley G, Longo LD. Fetal cerebral blood flow, electrocorticographic activity, and oxygenation: responses to acute hypoxia. J Physiol 2009; 587(Pt 9): 2033-47.

[108] Kill C, Torossian A, Freisburger C, et al. Basic life support with four different compression/ventilation ratios in a pig model: the need for ventilation. Resuscitation 2009; 80(9): 1060-5.

[109] Bekker A, Haile M, Li YS, et al. Nimodipine prevents memory impairment caused by nitroglycerin-induced hypotension in adult mice. Anesth Analg 2009; 109(6): 1943-8.

[110] Hemphill JC, 3rd, Morabito D, Farrant M, Manley GT. Brain tissue oxygen monitoring in intracerebral hemorrhage. Neurocrit Care 2005; 3(3): 260-70.

[111] Okonkwo DO, Wagner J, Melon DE, et al. Trans-sodium crocetinate increases oxygen delivery to brain parenchyma in rats on oxygen supplementation. Neurosci Lett 2003; 352(2): 97-100.

[112] Clausen T, Scharf A, Menzel M, et al. Influence of moderate and profound hyperventilation on cerebral blood flow, oxygenation and metabolism. Brain Res 2004; 1019(1-2): 113-23.

[113] Burger R, Bendszus M, Vince GH, Roosen K, Marmarou A. A new reproducible model of an epidural mass lesion in rodents. Part I: Characterization by neurophysiological monitoring, magnetic resonance imaging, and histopathological analysis. J Neurosurg 2002; 97(6): 1410-8.

[114] Carre E, Cantais E, Darbin O, et al. Technical aspects of an impact acceleration traumatic brain injury rat model with potential suitability for both microdialysis and $\mathrm{PtiO} 2$ monitoring. J Neurosci Methods 2004; 140(1-2): 23-8.

[115] Cavus E, Dorges V, Wagner-Berger H, et al. Changes of local brain tissue oxygen pressure after vasopressin during spontaneous circulation. Acta Neurochir (Wien) 2005; 147(3): 283-90; discussion 90.

[116] Gonzalez H, Hunter CJ, Bennet L, Power GG, Gunn AJ. Cerebral oxygenation during postasphyxial seizures in near-term fetal sheep. J Cereb Blood Flow Metab 2005; 25(7): 911-8.

[117] Scheufler KM, Lehnert A, Rohrborn HJ, Nadstawek J, Thees C. Individual value of brain tissue oxygen pressure, microvascular oxygen saturation, cytochrome redox level, and energy metabolites in detecting critically reduced cerebral energy state during acute changes in global cerebral perfusion. J Neurosurg Anesthesiol 2004; 16(3): 210-9.

[118] Hare GM, Hum KM, Kim SY, Barr A, Baker AJ, Mazer CD. Increased cerebral tissue oxygen tension after extensive hemodilution with a hemoglobin-based oxygen carrier. Anesth Analg 2004; 99(2): 528-35, table of contents.

[119] Maas AI, Fleckenstein W, de Jong DA, van Santbrink H. Monitoring cerebral oxygenation: experimental studies and preliminary clinical results of continuous monitoring of cerebrospinal fluid and brain tissue oxygen tension. Acta Neurochir Suppl (Wien) 1993; 59: 50-7.

[120] Rossi S, Balestreri M, Spagnoli D, et al. Oxygen delivery and oxygen tension in cerebral tissue during global cerebral ischaemia: a swine model. Acta Neurochir Suppl 2000; 76: 199-202.

[121] Lubbers DW, Baumgartl H. Heterogeneities and profiles of oxygen pressure in brain and kidney as examples of the pO2 distribution in the living tissue. Kidney Int 1997; 51(2): 372-80.

[122] Rossi S, Stocchetti N, Longhi L, et al. Brain oxygen tension, oxygen supply, and oxygen consumption during arterial hyperoxia in a model of progressive cerebral ischemia. J Neurotrauma 2001; 18(2): 163-74.

[123] Bein B, Cavus E, Stadlbauer KH, et al. Monitoring of cerebral oxygenation with near infrared spectroscopy and tissue oxygen partial pressure during cardiopulmonary resuscitation in pigs. Eur $\mathrm{J}$ Anaesthesiol 2006; 23(6): 501-9.

[124] Cavus E, Bein B, Dorges V, et al. Brain tissue oxygen pressure and cerebral metabolism in an animal model of cardiac arrest and cardiopulmonary resuscitation. Resuscitation 2006; 71(1): 97-106. 
[125] Demchenko IT, Luchakov YI, Moskvin AN, et al. Cerebral blood flow and brain oxygenation in rats breathing oxygen under pressure. J Cereb Blood Flow Metab 2005; 25(10): 1288-300.

[126] Hou H, Grinberg OY, Grinberg SA, Khan N, Dunn JF, Swartz HM. Cerebral PtO2, acute hypoxia, and volatile anesthetics in the rat brain. Adv Exp Med Biol 2005; 566: 179-85.

[127] Kwon TH, Sun D, Daugherty WP, Spiess BD, Bullock MR. Effect of perfluorocarbons on brain oxygenation and ischemic damage in an acute subdural hematoma model in rats. J Neurosurg 2005; 103(4): 724-30.

[128] Li M, Ratcliffe SJ, Knoll F, et al. Aging: impact upon local cerebral oxygenation and blood flow with acute isovolemic hemodilution. J Neurosurg Anesthesiol 2006; 18(2): 125-31.

[129] Muench E, Bauhuf C, Roth H, et al. Effects of positive endexpiratory pressure on regional cerebral blood flow, intracranial pressure, and brain tissue oxygenation. Crit Care Med 2005; 33(10): 2367-72.

[130] Ng I, Lee KK, Wong J. Brain tissue oxygenation monitoring in acute brain injury. Acta Neurochir Suppl 2005; 95: 447-51.

[131] Hoffman WE, Edelman G. Enhancement of brain tissue oxygenation during high dose isoflurane anesthesia in the dog. $\mathrm{J}$ Neurosurg Anesthesiol 2000; 12(2): 95-8.

[132] Hare GM, Worrall JM, Baker AJ, Liu E, Sikich N, Mazer CD. Beta2 adrenergic antagonist inhibits cerebral cortical oxygen delivery after severe haemodilution in rats. Br J Anaesth 2006; 97(5): 617-23.

[133] Rosenthal G, Morabito D, Cohen M, et al. Use of hemoglobinbased oxygen-carrying solution-201 to improve resuscitation parameters and prevent secondary brain injury in a swine model of traumatic brain injury and hemorrhage: laboratory investigation. J Neurosurg 2008; 108(3): 575-87.

[134] Perez-de-Sa V, Cunha-Goncalves D, Nordh A, et al. High brain tissue oxygen tension during ventilation with $100 \%$ oxygen after fetal asphyxia in newborn sheep. Pediatr Res 2009; 65(1): 57-61.

[135] Rigamonti A, McLaren AT, Mazer CD, et al. Storage of strainspecific rat blood limits cerebral tissue oxygen delivery during acute fluid resuscitation. Br J Anaesth 2008; 100(3): 357-64.

[136] Leal-Noval SR, Munoz-Gomez M, Arellano-Orden V, et al. Impact of age of transfused blood on cerebral oxygenation in male patients with severe traumatic brain injury. Crit Care Med 2008; 36(4): 1290-6.

[137] Geeraerts T, Friggeri A, Mazoit JX, Benhamou D, Duranteau J, Vigue B. Posttraumatic brain vulnerability to hypoxia-hypotension: the importance of the delay between brain trauma and secondary insult. Intensive Care Med 2008; 34(3): 551-60.

[138] Cavus E, Meybohm P, Dorges V, et al. Regional and local brain oxygenation during hemorrhagic shock: a prospective experimental study on the effects of small-volume resuscitation with norepinephrine. J Trauma 2008; 64(3): 641-8; discussion 8-9.

[139] Baker AJ, Park E, Hare GM, Liu E, Sikich N, Mazer DC. Effects of resuscitation fluid on neurologic physiology after cerebral trauma and hemorrhage. J Trauma 2008; 64(2): 348-57.

[140] Terajima K, Tsueshita T, Sakamoto A, Ogawa R. Fluid resuscitation with hemoglobin vesicles in a rabbit model of acute hemorrhagic shock. Shock 2006; 25(2): 184-9.

[141] Soukup J, Rieger A, Holz C, Miko I, Nemeth N, Menzel M. Temperature gradient between brain tissue and arterial blood mirrors the flow-metabolism relationship in uninjured brain: an experimental study. Acta Anaesthesiol Scand 2007; 51(7): 872-9.

[142] Manabe H, Okonkwo DO, Gainer JL, Clarke RH, Lee KS. Protection against focal ischemic injury to the brain by transsodium crocetinate. Laboratory investigation. J Neurosurg 2010; 113(4): 802-9.

[143] Dalen ML, Alme TN, Munkeby BH, et al. Early protective effect of hypothermia in newborn pigs after hyperoxic, but not after normoxic, reoxygenation. J Perinat Med 2010; 38(5): 545-56.

[144] Bao YH, Liang YM, Gao GY, Jiang JY. Lack of effect of moderate hypothermia on brain tissue oxygenation after acute intracranial hypertension in pigs. J Neurotrauma 2010; 27(2): 433-8.

[145] Wan JJ, Cohen MJ, Rosenthal G, et al. Refining resuscitation strategies using tissue oxygen and perfusion monitoring in critical organ beds. J Trauma 2009; 66(2): 353-7.

[146] Soeda M. Antegrade selective cerebral perfusion combined with deep hypothermic circulatory arrest on cerebral circulation: comparison between pulsatile and nonpulsatile blood flows. Ann Thorac Cardiovasc Surg 2007; 13(2): 93-101.
[147] Gilmer LK, Ansari MA, Roberts KN, Scheff SW. Age-related mitochondrial changes after traumatic brain injury. J Neurotrauma 2010; 27(5): 939-50.

[148] Givehchian M, Beschorner R, Ehmann C, et al. Neuroprotective effects of erythropoietin during deep hypothermic circulatory arrest. Eur J Cardiothorac Surg 2010; 37(3): 662-8.

[149] Ortiz-Prado E, Natah S, Srinivasan S, Dunn JF. A method for measuring brain partial pressure of oxygen in unanesthetized unrestrained subjects: the effect of acute and chronic hypoxia on brain tissue PO(2). J Neurosci Methods 2010; 193(2): 217-25.

[150] Ponticorvo A, Dunn AK. Simultaneous imaging of oxygen tension and blood flow in animals using a digital micromirror device. Opt Express 2010; 18(8): 8160-70.

[151] Vazquez AL, Fukuda M, Tasker ML, Masamoto K, Kim SG. Changes in cerebral arterial, tissue and venous oxygenation with evoked neural stimulation: implications for hemoglobin-based functional neuroimaging. J Cereb Blood Flow Metab 2010; 30(2): 428-39.

[152] Teranishi K, Scultetus A, Haque A, et al. Traumatic brain injury and severe uncontrolled haemorrhage with short delay pre-hospital resuscitation in a swine model. Injury 2012; 43(5): 585-93.

[153] Tyree K, Tyree M, DiGeronimo R. Correlation of brain tissue oxygen tension with cerebral near-infrared spectroscopy and mixed venous oxygen saturation during extracorporeal membrane oxygenation. Perfusion 2009; 24(5): 325-31.

[154] Vink R, Bahtia KD, Reilly PL. The relationship between intracranial pressure and brain oxygenation following traumatic brain injury in sheep. Acta Neurochir Suppl 2008; 102: 189-92.

[155] Nielsen TH, Engell SI, Johnsen RA, et al. Comparison between cerebral tissue oxygen tension and energy metabolism in experimental subdural hematoma. Neurocrit Care 2011; 15(3): 58592.

[156] Orakcioglu B, Kentar M, Uozumi Y, et al. Multiparametric characterisation of the perihemorrhagic zone in a porcine model of lobar ICH. Acta Neurochir Suppl 2011; 111: 19-23.

[157] Raabe A, Gottschalk A, Hommel M, Dubben HH, Strandl T. No effect of the hemoglobin solution HBOC-201 on the response of the rat $\mathrm{R} 1 \mathrm{H}$ tumor to fractionated irradiation. Strahlenther Onkol 2005; 181(11): 730-7.

[158] Becker A, Kuhnt T, Liedtke H, Krivokuca A, Bloching M, Dunst J. Oxygenation measurements in head and neck cancers during hyperbaric oxygenation. Strahlenther Onkol 2002; 178(2): 105-8.

[159] Taskapilioglu MO, Alkan T, Goren B, et al. Neuronal protective effects of focal ischemic pre- and/or postconditioning on the model of transient focal cerebral ischemia in rats. J Clin Neurosci 2009; 16(5): 693-7.

[160] Westermaier T, Jauss A, Eriskat J, Kunze E, Roosen K. Timecourse of cerebral perfusion and tissue oxygenation in the first $6 \mathrm{~h}$ after experimental subarachnoid hemorrhage in rats. J Cereb Blood Flow Metab 2009; 29(4): 771-9.

[161] Friess SH, Ralston J, Eucker SA, Helfaer MA, Smith C, Margulies SS. Neurocritical care monitoring correlates with neuropathology in a swine model of pediatric traumatic brain injury. Neurosurgery 2011; 69(5): 1139-47; discussion 47.

[162] Murakami Y, Wei G, Yang X, et al. Brain oxygen tension monitoring following penetrating ballistic-like brain injury in rats. $J$ Neurosci Methods 2012; 203(1): 115-21.

[163] Dunn JF, Khan MN, Hou HG, et al. Cerebral oxygenation in awake rats during acclimation and deacclimation to hypoxia: an in vivo electron paramagnetic resonance study. High Alt Med Biol 2011; 12(1): 71-7.

[164] Purins K, Sedigh A, Molnar C, et al. Standardized experimental brain death model for studies of intracranial dynamics, organ preservation, and organ transplantation in the pig. Crit Care Med 2011;39(3): 512-7.

[165] Grozinger G, Schenk M, Morgalla MH, Thiel C, Thiel K, Schuhmann MU. The values of cerebrovascular pressure reactivity and brain tissue oxygen pressure reactivity in experimental anhepatic liver failure. Neurocrit Care 2012; 17(2): 271-80.

[166] Grozinger G, Schenk M, Thiel C, Thiel K, Morgalla $M H$, Schuhmann MU. Is P(br)O (2) pressure reactivity index (ORx) dependent on the type of oxygen probe? An in vivo study. Acta Neurochir Suppl 2012; 114: 173-6.

[167] Unekawa M, Tomita M, Tomita Y, Toriumi H, Suzuki N. Sustained decrease and remarkable increase in red blood cell velocity in intraparenchymal capillaries associated with potassium- 
induced cortical spreading depression. Microcirculation 2012; 19(2): 166-74.

[168] Duchs R, Foitzik T. Possible pitfalls in the interpretation of microcirculatory measurements. A comparative study using intravital microscopy, spectroscopy and polarographic pO2 measurements. Eur Surg Res 2008; 40(1): 47-54.

[169] Schroeder JL, Highsmith JM, Young HF, Mathern BE. Reduction of hypoxia by perfluorocarbon emulsion in a traumatic spinal cord injury model. J Neurosurg Spine 2008; 9(2): 213-20.

[170] Russell DM, Garry EM, Taberner AJ, et al. A fully implantable telemetry system for the chronic monitoring of brain tissue oxygen in freely moving rats. J Neurosci Methods 2011; 204(2): 242-8.

[171] Verweij BH, Amelink GJ, Muizelaar JP. Current concepts of cerebral oxygen transport and energy metabolism after severe traumatic brain injury. Prog Brain Res 2007; 161: 111-24.

[172] Haitsma IK, Maas AI. Monitoring cerebral oxygenation in traumatic brain injury. Prog Brain Res 2007; 161: 207-16.

[173] Albano C, Comandante L, Nolan S. Innovations in the management of cerebral injury. Crit Care Nurs Q 2005; 28(2): 135-49.

[174] Alessandri B, Hoelper BM, Behr R, Kempski O. Accuracy and stability of temperature probes for intracranial application. J Neurosci Methods 2004; 139(2): 161-5.

[175] Belda FJ, Aguilar G, Soro M, Maruenda A. (Ventilatory management of the severely brain-injured patient). Rev Esp Anestesiol Reanim 2004; 51(3): 143-50.

[176] Hartl R, Bardt TF, Kiening KL, Sarrafzadeh AS, Schneider GH, Unterberg AW. Mannitol decreases ICP but does not improve brain-tissue pO2 in severely head-injured patients with intracranial hypertension. Acta Neurochir Suppl 1997; 70: 40-2.

[177] Hoelper BM, Alessandri B, Heimann A, Behr R, Kempski O. Brain oxygen monitoring: in vitro accuracy, long-term drift and responsetime of Licox- and Neurotrend sensors. Acta Neurochir (Wien) 2005; 147(7): 767-74.

[178] Lang EW, Czosnyka M, Mehdorn HM. Tissue oxygen reactivity and cerebral autoregulation after severe traumatic brain injury. Crit Care Med 2003; 31(1): 267-71.

[179] Rothoerl RD, Faltermeier R, Burger R, Woertgen C, Brawanski A. Dynamic correlation between tissue PO2 and near infrared spectroscopy. Acta Neurochir Suppl 2002; 81: 311-3.

[180] Sarrafzadeh AS, Kiening KL, Bardt TF, Hartl R, Schneider GH, Unterberg AW. (Monitoring cerebral oxygenation: a methodological comparison). Anasthesiol Intensivmed Notfallmed Schmerzther 1997; 32(2 Suppl): S224-30. [Monitoring der zerebralen Oxygenierung: Ein Methodenvergleich].

[181] Sarrafzadeh AS, Kiening KL, Bardt TF, Schneider GH, Unterberg AW, Lanksch WR. Cerebral oxygenation in contusioned vs nonlesioned brain tissue: monitoring of PtiO2 with Licox and Paratrend. Acta Neurochir Suppl 1998; 71: 186-9.

[182] Sarrafzadeh AS, Peltonen EE, Kaisers U, Kuchler I, Lanksch WR, Unterberg AW. Secondary insults in severe head injury--do multiply injured patients do worse? Crit Care Med 2001; 29(6): 1116-23.

[183] Schneider GH, Sarrafzadeh AS, Kiening KL, Bardt TF, Unterberg AW, Lanksch WR. Influence of hyperventilation on brain tissue$\mathrm{PO} 2, \mathrm{PCO} 2$, and $\mathrm{pH}$ in patients with intracranial hypertension. Acta Neurochir Suppl 1998; 71: 62-5.

[184] Unterberg AW, Kiening KL, Hartl R, Bardt T, Sarrafzadeh AS, Lanksch WR. Multimodal monitoring in patients with head injury: evaluation of the effects of treatment on cerebral oxygenation. J Trauma 1997; 42(5 Suppl): S32-7.

[185] Unterberg AW, Sarrafzadeh AS, Lanksch WR. (Skull-brain injury in polytrauma--results of neurosurgery). Anasthesiol Intensivmed Notfallmed Schmerzther 1999; 34 Suppl 1: S13-9. [Das SchadelHirn-Trauma im Rahmen des Polytraumas--Aufgaben der Neurochirurgie].

[186] Vespa PM. The implications of cerebral ischemia and metabolic dysfunction for treatment strategies in neurointensive care. Curr Opin Crit Care 2006; 12(2): 119-23.

[187] Stiefel MF, Udoetuk JD, Spiotta AM, et al. Conventional neurocritical care and cerebral oxygenation after traumatic brain injury. J Neurosurg 2006; 105(4): 568-75.

[188] Sakowitz OW, Unterberg AW. Detecting and treating microvascular ischemia after subarachnoid hemorrhage. Curr Opin Crit Care 2006; 12(2): 103-11.
[189] Nicholls TP, Shoemaker WC, Wo CC, Gruen JP, Amar A, Dang AB. Survival, hemodynamics, and tissue oxygenation after head trauma. J Am Coll Surg 2006; 202(1): 120-30.

[190] Dunn IF, Ellegala DB, Kim DH, Litvack ZN. Neuromonitoring in neurological critical care. Neurocrit Care 2006; 4(1): 83-92.

[191] Dunn IF, Ellegala DB, Fox JF, Kim DH. Principles of cerebral oxygenation and blood flow in the neurological critical care unit Neurocrit Care 2006; 4(1): 77-82.

[192] Nortje J, Gupta AK. The role of tissue oxygen monitoring in patients with acute brain injury. Br J Anaesth 2006; 97(1): 95-106.

[193] Tisdall MM, Tachtsidis I, Leung TS, Elwell CE, Smith M. Increase in cerebral aerobic metabolism by normobaric hyperoxia after traumatic brain injury. J Neurosurg 2008; 109(3): 424-32.

[194] Rosenthal G, Hemphill JC, Sorani M, et al. The role of lung function in brain tissue oxygenation following traumatic brain injury. J Neurosurg 2008; 108(1): 59-65.

[195] Timmons SD. Current trends in neurotrauma care. Crit Care Med 2010; 38(9 Suppl): S431-44.

[196] Perez-Barcena J, Ibanez J, Brell M, et al. Lack of correlation among intracerebral cytokines, intracranial pressure, and brain tissue oxygenation in patients with traumatic brain injury and diffuse lesions. Crit Care Med. 2011; 39(3): 533-40.

[197] Vilalta A, Sahuquillo J, Merino MA, et al. Normobaric hyperoxia in traumatic brain injury: does brain metabolic state influence the response to hyperoxic challenge? J Neurotrauma 2011; 28(7): 1139-48.

[198] Mulvey JM, Dorsch NW, Mudaliar Y, Lang EW. Multimodality monitoring in severe traumatic brain injury: the role of brain tissue oxygenation monitoring. Neurocrit Care 2004; 1(3): 391-402.

[199] Lang EW, Lagopoulos J, Griffith J, et al. Cerebral vasomotor reactivity testing in head injury: the link between pressure and flow. J Neurol Neurosurg Psychiatry 2003; 74(8): 1053-9.

[200] Adamides AA, Winter CD, Lewis PM, Cooper DJ, Kossmann T, Rosenfeld JV. Current controversies in the management of patients with severe traumatic brain injury. ANZ J Surg 2006; 76(3): 16374.

[201] Chan MT, Boet R, Ng SC, Poon WS, Gin T. Magnesium sulfate for brain protection during temporary cerebral artery occlusion. Acta Neurochir Suppl 2005; 95: 107-11.

[202] Yan Y, Tang W, Deng Z, Zhong D, Yang G. Cerebral oxygen metabolism and neuroelectrophysiology in a clinical study of severe brain injury and mild hypothermia. J Clin Neurosci 2010; 17(2): 196-200.

[203] Korsic M, Jugovic D, Kremzar B. Intracranial pressure and biochemical indicators of brain damage: follow-up study. Croat Med J 2006; 47(2): 246-52.

[204] Pachl J, Haninec P, Tencer T, et al. The effect of subarachnoid sodium nitroprusside on the prevention of vasospasm in subarachnoid haemorrhage. Acta Neurochir Suppl 2005; 95: 141-5.

[205] Boret H, Fesselet J, Meaudre E, Gaillard PE, Cantais E. Cerebral microdialysis and $\mathrm{P}(\mathrm{ti}) \mathrm{O} 2$ for neuro-monitoring before decompressive craniectomy. Acta Anaesthesiol Scand 2006; 50(2): 252-4.

[206] Joly LM, Mertes PM. (Monitoring of cerebral oxygenation with SvjO(2) or PtiO(2)). Ann Fr Anesth Reanim 2006; 25(7): 748-54. [Interet du monitorage de l'oxygenation cerebrale par $\operatorname{SvjO}(2)$ ou $\mathrm{PtiO}(2)]$.

[207] Paraforou T, Paterakis K, Fountas K, et al. Cerebral perfusion pressure, microdialysis biochemistry and clinical outcome in patients with traumatic brain injury. BMC Res Notes 2011; 4: 540.

[208] Rao GS, Durga P. Changing trends in monitoring brain ischemia: from intracranial pressure to cerebral oximetry. Curr Opin Anaesthesiol 2011; 24(5): 487-94.

[209] Masamoto K, Tanishita K. Oxygen transport in brain tissue. J Biomech Eng 2009; 131(7): 074002.

[210] Petrikov SS, Titova IV, Guseinova Kh T, Solodov AA, Khamidova LT, Krylov VV. Intracranial pressure, cerebral perfusion and metabolism in acute period of intracranial hemorrhage. $\mathrm{Zh} \mathrm{Vopr}$ Neirokhir Im N N Burdenko 2009; 1: 11-7.

[211] Taranova, II, Kokhno VN. (Brain edema treatment procedure using continuous controlled infusion of mannitol in neurosurgical patients). Anesteziol Reanimatol 2010; (4): 29-34.

[212] Ho CL, Wang CM, Lee KK, Ng I, Ang BT. Cerebral oxygenation, vascular reactivity, and neurochemistry following decompressive craniectomy for severe traumatic brain injury. J Neurosurg 2008; 108(5): 943-9. 
[213] Feng M, Loy LY, Zhang F, et al. Go green! Reusing brain monitoring data containing missing values: a feasibility study with traumatic brain injury patients. Acta Neurochir Suppl 2012; 114: 51-9.

[214] Dostanic MM, Stosic MM, Milakovic BD, et al. (New trends in neuromonitoring patients with with aneurysmal subarachnoid haemorrhage). Acta Chir Iugosl 2008; 55(2): 69-74.

[215] Purins K, Enblad P, Sandhagen B, Lewen A. Brain tissue oxygen monitoring: a study of in vitro accuracy and stability of NeuroventPTO and Licox sensors. Acta Neurochir (Wien) 2010; 152(4): 6818.

[216] Reinert M, Andres RH, Fuhrer M, Muller A, Schaller B, Widmer H. Online correlation of spontaneous arterial and intracranial pressure fluctuations in patients with diffuse severe head injury. Neurol Res 2007; 29(5): 455-62.

[217] Oddo M, Levine JM, Frangos S, et al. Brain lactate metabolism in humans with subarachnoid hemorrhage. Stroke 2012; 43(5): 141821.

[218] Lin JW, Lin CM, Tsai JT, Hung KS, Hung CC, Chiu WT. Neurotrauma research in Taiwan. Acta Neurochir Suppl 2008; 101: 113-7.

[219] Rockswold GL, Solid CA, Paredes-Andrade E, Rockswold SB, Jancik JT, Quickel RR. Hypertonic saline and its effect on intracranial pressure, cerebral perfusion pressure, and brain tissue oxygen. Neurosurgery 2009; 65(6): 1035-41; discussion 41-2.

[220] Pascual JL, Maloney-Wilensky E, Reilly PM, et al. Resuscitation of hypotensive head-injured patients: is hypertonic saline the answer? Am Surg 2008; 74(3): 253-9.

[221] Reithmeier T, Lohr M, Pakos P, Ketter G, Ernestus RI. Relevance of ICP and ptiO(2) for indication and timing of decompressive craniectomy in patients with malignant brain edema. Acta Neurochir (Wien) 2005; 147(9): 947-52.

[222] Jaeger M, Schuhmann MU, Soehle M, Meixensberger J. Continuous assessment of cerebrovascular autoregulation after traumatic brain injury using brain tissue oxygen pressure reactivity. Crit Care Med 2006; 34(6): 1783-8.

[223] Hlatky R, Valadka AB, Robertson CS. Intracranial pressure response to induced hypertension: role of dynamic pressure autoregulation. Neurosurgery 2005; 57(5): 917-23; discussion -23.

[224] Figaji AA, Zwane E, Fieggen AG, Peter JC, Leroux PD. Acute clinical grading in pediatric severe traumatic brain injury and its association with subsequent intracranial pressure, cerebral perfusion pressure, and brain oxygenation. Neurosurg Focus 2008; 25(4): E4.

[225] Johnston AJ, Steiner LA, Chatfield DA, et al. Effect of cerebral perfusion pressure augmentation with dopamine and norepinephrine on global and focal brain oxygenation after traumatic brain injury. Intensive Care Med 2004; 30(5): 791-7.

[226] Stiefel MF, Spiotta A, Gracias VH, et al. Reduced mortality rate in patients with severe traumatic brain injury treated with brain tissue oxygen monitoring. J Neurosurg 2005; 103(5): 805-11.

[227] Stocchetti N, Protti A, Lattuada M, et al. Impact of pyrexia on neurochemistry and cerebral oxygenation after acute brain injury. J Neurol Neurosurg Psychiatry 2005; 76(8): 1135-9.

[228] Sookplung P, Siriussawakul A, Malakouti A, et al. Vasopressor use and effect on blood pressure after severe adult traumatic brain injury. Neurocrit Care 2011; 15(1): 46-54.

[229] Helbok R, Kurtz P, Schmidt MJ, et al. Effects of the neurological wake-up test on clinical examination, intracranial pressure, brain metabolism and brain tissue oxygenation in severely brain-injured patients. Crit Care 2012; 16(6): R226.

[230] Nortje J, Coles JP, Timofeev I, et al. Effect of hyperoxia on regional oxygenation and metabolism after severe traumatic brain injury: preliminary findings. Crit Care Med 2008; 36(1): 273-81.

[231] Sarrafzadeh AS, Kiening KL, Unterberg AW. Neuromonitoring: brain oxygenation and microdialysis. Curr Neurol Neurosci Rep 2003; 3(6): 517-23.

[232] Sarrafzadeh AS, Kiening KL, Callsen TA, Unterberg AW. Metabolic changes during impending and manifest cerebral hypoxia in traumatic brain injury. Br J Neurosurg 2003; 17(4): 3406.

[233] De Georgia MA, Deogaonkar A. Multimodal monitoring in the neurological intensive care unit. Neurologist 2005; 11(1): 45-54.

[234] Clausen T, Alves OL, Reinert M, Doppenberg E, Zauner A, Bullock R. Association between elevated brain tissue glycerol levels and poor outcome following severe traumatic brain injury. $\mathrm{J}$ Neurosurg 2005; 103(2): 233-8.

[235] Al-Rawi PG, Zygun D, Tseng MY, Hutchinson PJ, Matta BF, Kirkpatrick PJ. Cerebral blood flow augmentation in patients with severe subarachnoid haemorrhage. Acta Neurochir Suppl 2005; 95: $123-7$.

[236] Kett-White R, Hutchinson PJ, Al-Rawi PG, Gupta AK, Pickard JD, Kirkpatrick PJ. Adverse cerebral events detected after subarachnoid hemorrhage using brain oxygen and microdialysis probes. Neurosurgery 2002; 50(6): 1213-21; discussion 21-2.

[237] Helbok R, Ko SB, Schmidt JM, et al. Global cerebral edema and brain metabolism after subarachnoid hemorrhage. Stroke 2011; 42(6): 1534-9.

[238] Meierhans R, Brandi G, Fasshauer M, et al. Arterial lactate above 2 $\mathrm{mM}$ is associated with increased brain lactate and decreased brain glucose in patients with severe traumatic brain injury. Minerva Anestesiol 2012; 78(2): 185-93.

[239] Puccio AM, Hoffman LA, Bayir H, et al. Effect of short periods of normobaric hyperoxia on local brain tissue oxygenation and cerebrospinal fluid oxidative stress markers in severe traumatic brain injury. J Neurotrauma 2009; 26(8): 1241-9.

[240] Hlatky R, Valadka AB, Gopinath SP, Robertson CS. Brain tissue oxygen tension response to induced hyperoxia reduced in hypoperfused brain. J Neurosurg 2008; 108(1): 53-8.

[241] Soukup J, Bramsiepe I, Brucke M, Sanchin L, Menzel M. Evaluation of a bedside monitor of regional $\mathrm{CBF}$ as a measure of $\mathrm{CO} 2$ reactivity in neurosurgical intensive care patients. J Neurosurg Anesthesiol 2008; 20(4): 249-55.

[242] Rosenthal G, Sanchez-Mejia RO, Phan N, Hemphill JC, 3rd, Martin C, Manley GT. Incorporating a parenchymal thermal diffusion cerebral blood flow probe in bedside assessment of cerebral autoregulation and vasoreactivity in patients with severe traumatic brain injury. J Neurosurg 2011; 114(1): 62-70.

[243] Leal-Noval SR, Cayuela A, Arellano-Orden V, et al. Invasive and noninvasive assessment of cerebral oxygenation in patients with severe traumatic brain injury. Intensive Care Med 2010; 36(8): 1309-17.

[244] Hartings JA, Gugliotta M, Gilman C, Strong AJ, Tortella FC, Bullock MR. Repetitive cortical spreading depolarizations in a case of severe brain trauma. Neurol Res 2008; 30(8): 876-82.

[245] Doll H, Davies N, Douglas SL, et al. One sensor fits all--a new approach in monitoring brain physiology. Adv Exp Med Biol 2009; 645: $175-80$.

[246] Dunn JF, Wu Y, Zhao Z, Srinivasan S, Natah SS. Training the brain to survive stroke. PloS ONE 2012; 7(9): e45108.

[247] Klein KU, Boehme S, Hartmann EK, et al. A novel technique for monitoring of fast variations in brain oxygen tension using an uncoated fluorescence quenching probe (Foxy AL-300). J Neurosurg Anesthesiol 2011; 23(4): 341-6.

[248] Meixensberger J, Baunach S, Amschler J, Dings J, Roosen K. Influence of body position on tissue-pO2, cerebral perfusion pressure and intracranial pressure in patients with acute brain injury. Neurol Res 1997; 19(3): 249-53.

[249] van Santbrink H, Maas AI, Avezaat CJ. Continuous monitoring of partial pressure of brain tissue oxygen in patients with severe head injury. Neurosurgery 1996; 38(1): 21-31.

[250] Low D, Kuralmani V, Ng SK, Lee KK, Ng I, Ang BT. Prediction of outcome utilizing both physiological and biochemical parameters in severe head injury. J Neurotrauma 2009; 26(8): 1177-82.

[251] Lubillo S, Blanco J, Lopez $\mathrm{P}$, et al. Does decompressive craniectomy improve other parameters besides ICP? Effects of the decompressive craniectomy on tissular pressure?. Med Intensiva 2011; 35(3): 166-9. [Inverted question markMejora la craniectomia descompresiva otros parametros ademas de la PIC? Efectos de la craniectomia descompresiva en la presion tisular].

[252] Ponce LL, Pillai S, Cruz J, et al. Position of probe determines prognostic information of brain tissue PO2 in severe traumatic brain injury. Neurosurgery 2012; 70(6): 1492-502; discussion 5023.

[253] Longhi L, Pagan F, Valeriani V, et al. Monitoring brain tissue oxygen tension in brain-injured patients reveals hypoxic episodes in normal-appearing and in peri-focal tissue. Intensive Care Med 2007; 33(12): 2136-42. 
[254] van den Brink WA, van Santbrink H, Steyerberg EW, et al. Brain oxygen tension in severe head injury. Neurosurgery $2000 ; 46(4)$ : 868-76; discussion 76-8.

[255] Eriksson EA, Barletta JF, Figueroa BE, et al. The first 72 hours of brain tissue oxygenation predicts patient survival with traumatic brain injury. J Trauma Acute Care Surg 2012; 72(5): 1345-9.

[256] Kiening KL, Unterberg AW, Bardt TF, Schneider GH, Lanksch WR. Monitoring of cerebral oxygenation in patients with severe head injuries: brain tissue PO2 versus jugular vein oxygen saturation. J Neurosurg 1996; 85(5): 751-7.

[257] Baumgartl H, Lubbers DW. Microaxial needle sensors for polarographic measurements of local $\mathrm{O} 2$ in the cellular range of living tissue. In: Gnaiger E, Foerstner H, Eds. Polarographic Oxygen Sensors. New York: Springer Verlag 1983. pp. 37-65.

[258] Jaeger M, Dengl M, Meixensberger J, Schuhmann MU. Effects of cerebrovascular pressure reactivity-guided optimization of cerebral perfusion pressure on brain tissue oxygenation after traumatic brain injury. Crit Care Med 2010; 38(5): 1343-7.

[259] Jaeger M, Soehle M, Meixensberger J. Brain tissue oxygen (PtiO2): a clinical comparison of two monitoring devices. Acta Neurochir Suppl 2005; 95: 79-81.

[260] Johnston AJ, Steiner LA, Coles JP, et al. Effect of cerebral perfusion pressure augmentation on regional oxygenation and metabolism after head injury. Crit Care Med 2005; 33(1): 189-95; discussion 255-7.

[261] Dengler J, Frenzel C, Vajkoczy P, Wolf S, Horn P. Cerebral tissue oxygenation measured by two different probes: challenges and interpretation. Intensive Care Med 2011; 37(11): 1809-15.

[262] Purins K, Enblad P, Wiklund L, Lewen A. Brain tissue oxygenation and cerebral perfusion pressure thresholds of ischemia in a standardized pig brain death model. Neurocrit Care 2012; 16(3): 462-9.

[263] Stein DM, Lindell AL, Murdock KR, et al. Use of serum biomarkers to predict cerebral hypoxia after severe traumatic brain injury. J Neurotrauma 2012; 29(6): 1140-9.

[264] Bratton SL, Chestnut RM, Ghajar J, et al. Guidelines for the management of severe traumatic brain injury. X. Brain oxygen monitoring and thresholds. J Neurotrauma 2007; 24 Suppl 1: S6570 .

[265] Valadka AB, Gopinath SP, Contant CF, Uzura M, Robertson CS. Relationship of brain tissue PO2 to outcome after severe head injury. Crit Care Med 1998; 26(9): 1576-81.

[266] Bowles AP, Pasierb L, Simunich T, Updyke M. Implications of neurophysiological parameters in persons with severe brain injury with respect to improved patient outcomes: a retrospective review. Brain injury : (BI) 2012; 26(12): 1415-24.

[267] Katsnelson M, Mackenzie L, Frangos S, et al. Are initial radiographic and clinical scales associated with subsequent intracranial pressure and brain oxygen levels after severe traumatic brain injury? Neurosurgery 2012; 70(5): 1095-105; discussion 105.

[268] Oddo M, Levine JM, Mackenzie L, et al. Brain hypoxia is associated with short-term outcome after severe traumatic brain injury independently of intracranial hypertension and low cerebral perfusion pressure. Neurosurgery 2011; 69(5): 1037-45; discussion 45.

[269] Meixensberger J, Renner C, Simanowski R, Schmidtke A, Dings J, Roosen K. Influence of cerebral oxygenation following severe head injury on neuropsychological testing. Neurol Res 2004; 26(4): 4147.

[270] Narotam PK, Morrison JF, Nathoo N. Brain tissue oxygen monitoring in traumatic brain injury and major trauma: outcome analysis of a brain tissue oxygen-directed therapy. J Neurosurg 2009; 111(4): 672-82.

[271] McCarthy MC, Moncrief H, Sands JM, et al. Neurologic outcomes with cerebral oxygen monitoring in traumatic brain injury. Surgery 2009; 146(4): 585-90; discussion 90-1.

[272] Martini RP, Deem S, Yanez ND, et al. Management guided by brain tissue oxygen monitoring and outcome following severe traumatic brain injury. J Neurosurg 2009; 111(4): 644-9.

[273] Rose JC, Neill TA, Hemphill JC, 3rd. Continuous monitoring of the microcirculation in neurocritical care: an update on brain tissue oxygenation. Curr Opin Crit Care 2006; 12(2): 97-102.

[274] Pascual JL, Georgoff P, Maloney-Wilensky E, et al. Reduced brain tissue oxygen in traumatic brain injury: are most commonly used interventions successful? J Trauma 2011; 70(3): 535-46.
[275] Dings J, Meixensberger J, Amschler J, Roosen K. Continuous monitoring of brain tissue PO2: a new tool to minimize the risk of ischemia caused by hyperventilation therapy. Zentralbl Neurochir 1996; 57(4): 177-83.

[276] Rangel-Castilla L, Lara LR, Gopinath S, Swank PR, Valadka A, Robertson C. Cerebral hemodynamic effects of acute hyperoxia and hyperventilation after severe traumatic brain injury. J Neurotrauma 2010; 27(10): 1853-63.

[277] Dings J, Meixensberger J, Amschler J, Hamelbeck B, Roosen K. Brain tissue pO2 in relation to cerebral perfusion pressure, TCD findings and TCD-CO2-reactivity after severe head injury. Acta Neurochir (Wien) 1996; 138(4): 425-34.

[278] Raabe A, Beck J, Keller M, Vatter H, Zimmermann M, Seifert V. Relative importance of hypertension compared with hypervolemia for increasing cerebral oxygenation in patients with cerebral vasospasm after subarachnoid hemorrhage. J Neurosurg 2005; 103(6): 974-81.

[279] Cerejo A, Silva PA, Vilarinho A, Dias C, Vaz R. Intraoperative brain oxygenation monitoring and vasospasm in aneurysmal subarachnoid hemorrhage. Neurol Res 2012; 34(2): 181-6.

[280] Deshaies EM, Jacobsen W, Singla A, Li F, Gorji R. Brain tissue oxygen monitoring to assess reperfusion after intra-arterial treatment of aneurysmal subarachnoid hemorrhage-induced cerebral vasospasm: a retrospective study. Am J Neuroradiol 2012; 33(7): 1411-5.

[281] Helbok R, Shaker E, Beer R, et al. High dose erythropoietin increases brain tissue oxygen tension in severe vasospasm after subarachnoid hemorrhage. BMC Neurol 2012; 12: 32

[282] Ledwith MB, Bloom S, Maloney-Wilensky E, Coyle B, Polomano $\mathrm{RC}$, Le Roux PD. Effect of body position on cerebral oxygenation and physiologic parameters in patients with acute neurological conditions. J Neurosci Nurs 2010; 42(5): 280-7.

[283] Swanson EW, Mascitelli J, Stiefel M, et al. Patient transport and brain oxygen in comatose patients. Neurosurgery 2010; 66(5): 92531; discussion 31-2.

[284] Peace K, Maloney-Wilensky E, Frangos S, et al. Portable head CT scan and its effect on intracranial pressure, cerebral perfusion pressure, and brain oxygen. J Neurosurg 2011; 114(5): 1479-84.

[285] Stuart RM, Claassen J, Schmidt M, et al. Multimodality neuromonitoring and decompressive hemicraniectomy after subarachnoid hemorrhage. Neurocrit Care 2011; 15(1): 146-50.

[286] Jaeger M, Soehle M, Meixensberger J. Improvement of brain tissue oxygen and intracranial pressure during and after surgical decompression for diffuse brain oedema and space occupying infarction. Acta Neurochir Suppl 2005; 95: 117-8.

[287] Timofeev I, Dahyot-Fizelier C, Keong N, et al. Ventriculostomy for control of raised ICP in acute traumatic brain injury. Acta Neurochir Suppl 2008; 102: 99-104.

[288] Wolf S, Martin H, Landscheidt JF, Rodiek SO, Schurer L, Lumenta CB. Continuous selective intraarterial infusion of nimodipine for therapy of refractory cerebral vasospasm. Neurocrit Care 2010; 12(3): 346-51

[289] Narotam PK, Puri V, Roberts JM, Taylon C, Vora Y, Nathoo N. Management of hypertensive emergencies in acute brain disease: evaluation of the treatment effects of intravenous nicardipine on cerebral oxygenation. J Neurosurg 2008; 109(6): 1065-74.

[290] Oddo M, Levine JM, Frangos S, et al. Effect of mannitol and hypertonic saline on cerebral oxygenation in patients with severe traumatic brain injury and refractory intracranial hypertension. J Neurol Neurosurg Psychiatry 2009; 80(8): 916-20.

[291] Ristagno G, Tang W, Huang L, et al. Epinephrine reduces cerebral perfusion during cardiopulmonary resuscitation. Crit Care Med 2009; 37(4): 1408-15.

[292] Chen HI, Malhotra NR, Oddo M, Heuer GG, Levine JM, LeRoux PD. Barbiturate infusion for intractable intracranial hypertension and its effect on brain oxygenation. Neurosurgery 2008; 63(5): 880-6; discussion 6-7.

[293] Kumar MA, Chanderraj R, Gant R, et al. Obesity is associated with reduced brain tissue oxygen tension after severe brain injury. Neurocrit Care 2012; 16(2): 286-93.

[294] McLeod AD, Igielman F, Elwell C, Cope M, Smith M. Measuring cerebral oxygenation during normobaric hyperoxia: a comparison of tissue microprobes, near-infrared spectroscopy, and jugular venous oximetry in head injury. Anesth Analg 2003; 97(3): 851-6.

[295] Tolias CM, Reinert M, Seiler R, Gilman C, Scharf A, Bullock MR. Normobaric hyperoxia--induced improvement in cerebral 
metabolism and reduction in intracranial pressure in patients with severe head injury: a prospective historical cohort-matched study. J Neurosurg 2004; 101(3): 435-44.

[296] Rockswold SB, Rockswold GL, Zaun DA, et al. A prospective, randomized clinical trial to compare the effect of hyperbaric to normobaric hyperoxia on cerebral metabolism, intracranial pressure, and oxygen toxicity in severe traumatic brain injury. $\mathrm{J}$ Neurosurg 2010; 112(5): 1080-94.

[297] Oddo M, Levine JM, Kumar M, et al. Anemia and brain oxygen after severe traumatic brain injury. Intensive Care Med. 2012; 38(9): 1497-504.

[298] Smith MJ, Stiefel MF, Magge S, et al. Packed red blood cell transfusion increases local cerebral oxygenation. Crit Care Med 2005; 33(5): 1104-8.

[299] Zygun DA, Nortje J, Hutchinson PJ, Timofeev I, Menon DK, Gupta AK. The effect of red blood cell transfusion on cerebral oxygenation and metabolism after severe traumatic brain injury. Crit Care Med 2009; 37(3): 1074-8.

[300] Arellano-Orden V, Leal-Noval SR, Cayuela A, et al. Gender influences cerebral oxygenation after red blood cell transfusion in patients with severe traumatic brain injury. Neurocrit Care 2011; 14(1): 18-23.

[301] Stuart RM, Helbok R, Kurtz P, et al. High-dose intra-arterial verapamil for the treatment of cerebral vasospasm after subarachnoid hemorrhage: prolonged effects on hemodynamic parameters and brain metabolism. Neurosurgery 2011; 68(2): 33745; discussion 45.

[302] Schmidt JM, Ko SB, Helbok R, et al. Cerebral perfusion pressure thresholds for brain tissue hypoxia and metabolic crisis after poorgrade subarachnoid hemorrhage. Stroke 2011; 42(5): 1351-6.

[303] Bohman LE, Heuer GG, Macyszyn L, et al. Medical management of compromised brain oxygen in patients with severe traumatic brain injury. Neurocrit Care 2011; 14(3): 361-9.

[304] Chen HI, Stiefel MF, Oddo M, et al. Detection of cerebral compromise with multimodality monitoring in patients with subarachnoid hemorrhage. Neurosurgery 2011; 69(1): 53-63; discussion.

[305] Marin-Caballos AJ, Murillo-Cabezas F, Cayuela-Dominguez A, et al. Cerebral perfusion pressure and risk of brain hypoxia in severe head injury: a prospective observational study. Crit Care 2005; 9(6): R670-6.

[306] Eriksson EA, Barletta JF, Figueroa BE, et al. Cerebral perfusion pressure and intracranial pressure are not surrogates for brain tissue oxygenation in traumatic brain injury. Clin Neurophysiol 2012; 123(6): 1255-60.

[307] Rohlwink UK, Zwane E, Fieggen AG, Argent AC, le Roux PD, Figaji AA. The relationship between intracranial pressure and brain oxygenation in children with severe traumatic brain injury. Neurosurgery 2012; 70(5): 1220-30; discussion 31 .

[308] Radolovich DK, Czosnyka M, Timofeev I, et al. Reactivity of brain tissue oxygen to change in cerebral perfusion pressure in head injured patients. Neurocrit Care 2009; 10(3): 274-9.

[309] Radolovich DK, Czosnyka M, Timofeev I, et al. Transient changes in brain tissue oxygen in response to modifications of cerebral perfusion pressure: an observational study. Anesth Analg 2010; 110(1): 165-73.

[310] Jaeger M. Different indices to assess cerebrovascular autoregulation have different dynamic properties. Neurocrit Care 2010; 13(1): 163-5.

[311] Timofeev I, Czosnyka M, Carpenter KL, et al. Interaction between brain chemistry and physiology after traumatic brain injury: impact of autoregulation and microdialysis catheter location. J Neurotrauma 2011; 28(6): 849-60.

[312] Hecht N, Fiss I, Wolf S, Barth M, Vajkoczy P, Woitzik J. Modified flow- and oxygen-related autoregulation indices for continuous monitoring of cerebral autoregulation. J Neurosci Methods 2011; 201(2): 399-403.

[313] Dengler J, Frenzel C, Vajkoczy P, Horn P, Wolf S. The Oxygen Reactivity Index and Its Relation to Sensor Technology in Patients with Severe Brain Lesions. Neurocrit Care 2012; [Epub ahead of print].

[314] Egea-Guerrero JJ, Gordillo-Escobar E, Revuelto-Rey J, et al. Clinical variables and neuromonitoring information (intracranial pressure and brain tissue oxygenation) as predictors of brain-death development after severe traumatic brain injury. Transplant proc 2012; 44(7): 2050-2.
[315] Figaji AA, Kent SJ. Brain tissue oxygenation in children diagnosed with brain death. Neurocrit Care 2010; 12(1): 56-61.

[316] Maloney-Wilensky E, Gracias V, Itkin A, et al. Brain tissue oxygen and outcome after severe traumatic brain injury: a systematic review. Crit Care Med 2009; 37(6): 2057-63.

[317] Dings J, Meixensberger J, Roosen K. Brain tissue pO2-monitoring: catheterstability and complications. Neurol Res 1997; 19(3): 241-5.

[318] Stewart C, Haitsma I, Zador Z, et al. The new Licox combined brain tissue oxygen and brain temperature monitor: assessment of in vitro accuracy and clinical experience in severe traumatic brain injury. Neurosurgery 2008; 63(6): 1159-64; discussion 64-5.

[319] Haitsma I, Rosenthal G, Morabito D, Rollins M, Maas AI, Manley GT. In vitro comparison of two generations of Licox and Neurotrend catheters. Acta Neurochir Suppl 2008; 102: 197-202.

[320] Stuart RM, Schmidt M, Kurtz P, et al. Intracranial multimodal monitoring for acute brain injury: a single institution review of current practices. Neurocrit Care 2010; 12(2): 188-98.

[321] Orakcioglu B, Sakowitz OW, Neumann JO, Kentar MM, Unterberg A, Kiening KL. Evaluation of a novel brain tissue oxygenation probe in an experimental swine model. Neurosurgery $2010 ; 67(6)$ : 1716-22; discussion 22-3.

[322] Deng1 M, Jaeger M, Renner C, Meixensberger J. Comparing brain tissue oxygen measurements and derived autoregulation parameters from different probes (Licox vs Raumedic). Acta Neurochir Suppl 2012; 114: 165-8.

[323] Morgalla MH, Haas R, Grozinger G, et al. Experimental comparison of the measurement accuracy of the $\operatorname{Licox}((\mathrm{R}))$ and Raumedic ((R)) Neurovent-PTO brain tissue oxygen monitors. Acta Neurochir Suppl 2012; 114: 169-72.

[324] Wolf S, Horn P, Frenzel C, Schurer L, Vajkoczy P, Dengler J. Comparison of a new brain tissue oxygenation probe with the established standard. Acta Neurochir Suppl 2012; 114: 161-4.

[325] Nangunoori R, Maloney-Wilensky E, Stiefel M, et al. Brain tissue oxygen-based therapy and outcome after severe traumatic brain injury: a systematic literature review. Neurocrit Care 2012; 17(1): $131-8$.

[326] Tran-Dinh A, Depret F, Vigue B. Brain tissue oxygen pressure, for what, for whom? Ann Fr Anesth Reanim 2012; 31(6): e137-43. [Pression tissulaire cerebrale en oxygene: pour quoi faire et pour qui?].

[327] Oddo M, Villa F, Citerio G. Brain multimodality monitoring: an update. Curr Opin Crit Care 2012; 18(2): 111-8.

[328] Keddie S, Rohman L. Reviewing the reliability, effectiveness and applications of Licox in traumatic brain injury. Nurs Crit Care 2012; 17(4): 204-12.

[329] Beynon C, Kiening KL, Orakcioglu B, Unterberg AW, Sakowitz OW. Brain tissue oxygen monitoring and hyperoxic treatment in patients with traumatic brain injury. J Neurotrauma 2012; 29(12): 2109-23.

[330] Maloney-Wilensky E, Le Roux P. The physiology behind direct brain oxygen monitors and practical aspects of their use. Childs Nerv Syst 2010; 26(4): 419-30.

[331] Komotar RJ, Schmidt JM, Starke RM, et al. Resuscitation and critical care of poor-grade subarachnoid hemorrhage. Neurosurgery 2009; 64(3): 397-410; discussion -1.

[332] Hession D. Management of traumatic brain injury: nursing practice guidelines for cerebral perfusion and brain tissue oxygenation (PbtO2) systems. Pediatr Nurs 2008; 34(6): 470-2.

[333] Marin-Caballos AJ, Murillo-Cabezas F, Dominguez-Roldan JM, Leal-Noval SR, Rincon-Ferrari MD, Munoz-Sanchez MA. (Monitoring of tissue oxygen pressure (PtiO2) in cerebral hypoxia: diagnostic and therapeutic approach). Med Intensiva 2008; 32(2): 81-90. [Monitorizacion de la presion tisular de oxigeno (PtiO2) en la hipoxia cerebral: aproximacion diagnostica y terapeutica].

[334] Werner C, Engelhard K. Pathophysiology of traumatic brain injury. Br J Anaesth 2007; 99(1): 4-9.

[335] Bhatia A, Gupta AK. Neuromonitoring in the intensive care unit. II. Cerebral oxygenation monitoring and microdialysis. Intensive Care Med 2007; 33(8) 1322-8.

[336] Stevens WJ. Multimodal monitoring: head injury management using SjvO2 and LICOX. J Neurosci Nurs 2004; 36(6): 332-9.

[337] Bader MK. Recognizing and treating ischemic insults to the brain: the role of brain tissue oxygen monitoring. Crit Care Nurs Clin North Am 2006; 18(2): 243-56, xi. 
[338] Vespa PM. Multimodality monitoring and telemonitoring in neurocritical care: from microdialysis to robotic telepresence. Curr Opin Crit Care 2005; 11(2): 133-8.

[339] Mazzeo AT, Bullock R. Monitoring brain tissue oxymetry: Will it change management of critically ill neurologic patients? J Neurol Sci 2007; 261(1-2): 1-9.

[340] Barazangi N, Hemphill JC, 3rd. Advanced cerebral monitoring in neurocritical care. Neurol India 2008; 56(4): 405-14.

[341] Diringer MN. Hyperoxia: good or bad for the injured brain? Curr Opin Crit Care 2008; 14(2): 167-71.

[342] Cecil S, Chen PM, Callaway SE, Rowland SM, Adler DE, Chen JW. Traumatic brain injury: advanced multimodal neuromonitoring from theory to clinical practice. Crit Care Nurs 2011; 31(2): 25-36; quiz 7.

[343] Dagal A, Lam AM. Cerebral blood flow and the injured brain: how should we monitor and manipulate it? Curr Opin Anaesthesiol 2011; 24(2): 131-7.
[344] Hemphill JC, Andrews P, De Georgia M, Medscape. Multimodal monitoring and neurocritical care bioinformatics. Nat Rev Neurol 2011; 7(8): 451-60.

[345] Stover JF. Actual evidence for neuromonitoring-guided intensive care following severe traumatic brain injury. Swiss Med Wkly 2011; 141: w13245.

[346] Wartenberg KE. Critical care of poor-grade subarachnoid hemorrhage. Curr Opin Crit Care 2011; 17(2): 85-93.

[347] Foster K, Stocker C, Schibler A. Controversies of prophylactic hypothermia and the emerging use of brain tissue oxygen tension monitoring and decompressive craniectomy in traumatic braininjured children. Aust Crit Care 2010; 23(1): 4-11.

[348] Rohlwink UK, Figaji AA. Methods of monitoring brain oxygenation. Childs Nerv Syst 2010; 26(4): 453-64.

[349] Wilensky EM, Bloom S, Leichter D, et al. Brain tissue oxygen practice guidelines using the LICOX CMP monitoring system. J Neurosci Nurs 2005; 37(5): 278-88.

(C) Lang and Jaeger; Licensee Bentham Open.

This is an open access article licensed under the terms of the Creative Commons Attribution Non-Commercial License (http://creativecommons.org/licenses/by-nc/ $3.0 /$ ) which permits unrestricted, non-commercial use, distribution and reproduction in any medium, provided the work is properly cited. 